\title{
Schizophrenia Aetiology and Drug Therapy: A Tale of Progressive Demystification and Strides in Management
}

\author{
Onaolapo A $\mathbf{Y}^{1}$, Onaolapo $\mathbf{O} \mathbf{J}^{2, *}$ \\ ${ }^{1}$ Behavioural Neuroscience/Neurobiology Unit, Department of Anatomy, Ladoke Akintola University of Technology, Nigeria \\ ${ }^{2}$ Behavioural Neuroscience/Neuropharmacology Unit, Department of Pharmacology, \\ Ladoke Akintola University of Technology, Nigeria
}

Copyright $\bigcirc 2018$ by authors, all rights reserved. Authors agree that this article remains permanently open access under the terms of the Creative Commons Attribution License 4.0 International License

\begin{abstract}
Schizophrenia is a chronic, debilitating and complex neuropsychiatric disorder which is known to be characterised by impairments in perception of reality, cognition, interpersonal relationships, mood and social/work function; and influenced by genes and the environment. Our understanding of the aetiology of schizophrenia and theories seeking to explain the accompanying changes in brain chemistry and structure has continued to undergo revisions, largely due to new insights from preclinical and clinical research. In this review, we discuss the evolution of our understanding of schizophrenia aetiopathogenesis as it relates to disease phenotype, symptom management and drug discovery. We also examine the important roles played by interactions between brain neurotransmitters and their receptors in disease expression and symptom management; and discuss how newer chapters in the management of the disease are being opened through the development and identification of newer disease-modifying and modulating agents.
\end{abstract}

Keywords Antipsychotic, Dementia Praecox, Mental Health, Neuroinflammation, Neurotransmitters, Neurodevelopment, Receptors

\section{Introduction}

Schizophrenia is a multifactorial mental health disorder that afflicts approximately $1 \%$ of the world's population, with slight geographical and cultural variations in incidence and lifetime prevalence [1-4]. It is characterised by impairments in: perception of reality, interpersonal relationships, mood, social/work function and neuro-cognitive function [5]; and influenced by a heterogeneous genetic, environmental [6] and neurobiological backgrounds [2-4]. Schizophrenia usually undergoes a fluctuating and/or enduring course which is worsened by co-morbidities [7, 8] and has an age of onset which is generally between adolescence and early adulthood [9]. In comparison to the general populace, schizophrenics have a two to three-fold higher mortality rate [10]. However, despite years of research, the aetiopathogenesis [11] or extent of heterogeneity [1] of schizophrenia remains incompletely understood; and there are suggestions that schizophrenia is usually an outcome of complex interactions between genetic and environmental factors [3, 6, 12-15]. In recent times, an emerging consensus proposes that schizophrenia should be regarded as a disease spectrum with multiple causes and disease phenotypes [1], rather than a single disease entity. Theories explaining the possible aetiopathogenesis of schizophrenia have been proposed, disproved or confirmed through the years. Of these, some have become the basis of therapeutic interventions (such as the use of dopamine receptor blockers). Recently, the 'two-hit' hypothesis suggests that an initial prenatal genetic or environmental factor disrupts aspects of brain development (a "first hit"), predisposing to the development of schizophrenia that may follow a major life event (a "second hit") occurring later in life $[1,13,16]$.

This review examines schizophrenia from a perspective of where we have been to where we are now; and with a particular focus on aetiopathogenesis as it relates to disease phenotypes, symptom management and trends in pharmacotherapy. We also examine the important roles played by brain neurotransmitter/ receptor interactions in disease phenotypes; and examine how relating neurotransmitter/ receptor dysfunctions with other known aetiological factors like inflammation or oxidative stress, may lead to the development and identification of newer drugs.

\section{Historical Perspective}

The historical 'beginnings' of schizophrenia is difficult to pinpoint, since the earliest references to mental illnesses with symptoms that are similar to schizophrenia are masked by a belief system that attributes the presence of 
strange behaviours to a demonic possession, or punishment for immoral behaviour. However, evidence for the presence of schizophrenia-related mental illnesses is probably as old as mankind, as revealed by the discovery of Stone-Age skulls with burr-holes drilled into them for the 'release of evil spirits'; a procedure now known as trepanation [17].

The earliest documented history of schizophrenia or schizophrenia-like symptomatology dates back to ancient Egypt, around the second millennium BC [17, 18]; while Hindu descriptions which can be found in the Atharva Veda date back to approximately 1400 BC [17]. In Greek mythology and the Homerian epics, all forms of mental illness or 'madness' were thought of as 'divine punishment'. However, by the time of Hippocrates (460-377 BC), mental illness became an object of scientific speculation. Hippocrates believed 'madness' was a consequence of an imbalance of the four bodily humours, and cure could only be achieved by rebalancing these humours with special diets, purgatives, and blood-lettings [18]; and for a while, the management of all mental illness followed the rules of 'humoral pathology', although a few scientists disagreed. Aretaios suggested that the origin of mental disorders might not be specifically localized, and that premorbid personality might play an important role in the aetiology of mental disorders $[17,18]$; an opinion that has become important in the diagnosis of schizophrenia in the $21^{\text {st }}$ century. Aristotle (384-322 BC) and Galen (129-216) both expanded on the humoral theories of Hippocrates, although Galen also believed that mental diseases could stem from disorders in the brain or be the consequence of a derangement in other organs $[17,18]$.

In the middle ages, only the university scholars had a rational and scientific attitude towards madness, while the general populace still held the firm belief that it was a trial or a punishment from a higher being. In $15^{\text {th }}$ century Europe, people with hallucinations and delusions were assumed to be possessed, and a number of women were thought to be witches and burnt at the stake. This however slowly gave way to asylums in the $16^{\text {th }}$ century as medical notions again gained momentum [17-19].

\subsection{Schizophrenia: Emil Kraepelin and Eugen Bleuler Era}

The word 'schizophrenia', as first mentioned by Eugen Bleuler, is just over a hundred years old [17, 20]; however, several developments led to the evolution of the name. By the middle of the 19th century, scientists began to have a better understanding of the disease concept; with a number of European psychiatrists describing a chronic disorder of unknown aetiology, predominantly affecting the young [17, 21]. In France, the terminology 'démence précoce' was coined by Morel, while Clouston (from Scotland) referred to it as "adolescent insanity." In 1851, Falvet described it as 'Folie Circulaire' meaning cyclical madness; while in
1871, Hecker (a German scientist) called it 'hebephrenia' referring to having a silly, undisciplined mind, a terminology he modelled after Hebe, the goddess of youth and frivolity [17, 19]. In 1874, Kahlbaum (another German scientist) described both catatonic and paranoid disorders of the mind, with the term catatonia referring to a movement disorder which is characterized by a mannequin-like muscle rigidity with unusual posturing and a pervading fear $[17,19]$.

In 1878, Emil Kraepelin integrated these various 'disorders' into a single nosological entity termed dementia praecox (DP) or 'dementia of early onset' referring to a common pattern of disease course culminating in a decline in behaviour and cognitive functioning/processing, occurring in a number of young patients [17, 19, 22]. The term praecox distinguishes it from other forms of dementia which occurred typically later in life. Kraepelin acknowledged the diverse nature of the various clinical scenarios classified under DP and identified four subtypes or nine clinical "forms," each connected one to another by very fluid transitions. Simple DP is marked by slow concomitant social decline, social withdrawal and apathy, paranoid DP is characterised by 'persecutory' delusions and an attendant fear, hebephrenic DP shows disorganized thinking, attention, language and memory deficits, and catatonic DP is characterized by a poverty of expression and movement, culminating in hallucinations and delusions [17, 19, 22-24].

In 1908, Eugen Bleuler began to raise strong objections to the use of the terminology DP and the classifications of this nosological entity. He contested the presence of a global dementing process, and in 1911coined the divisive term 'schizophrenia' from two words of Greek origin; schizo (split) and phrene (mind), to describe the fragmented thinking of the sufferers of the disorder. He defined schizophrenia using four "A's", which include 1) a diminished emotional response to stimuli or blunted Affect, 2) a disordered pattern of thought or loosening of Association, 3) Ambivalence which he described as an apparent inability to make decisions and; 4) Autism which is the loss of awareness of external events, and a morbid preoccupation with self. Bleuler went on to group the symptoms as either "positive" or "negative" $\mathrm{He}$ also acknowledged that the clinical subgroups of schizophrenia as described by Kraepelin were not "natural" nosological entities [19]. Bleuler argued the inclusion of Wernicke's motility psychoses, atypical depressive/manic states, reactive psychoses, and other kinds of nonorganic, non-affective psychotic disorders into a group of schizophrenias; thereby, suggesting the possibility of heredity as an aetiological factor [19, 25-27].

\subsection{Schizophrenia: Post-bleulerian Era}

The definition of schizophrenia has continued to evolve, as scientists and clinicians attempt to accurately define and characterize different types of mental illnesses. However, 
the absence of well-defined aetiologies would mean that classifications are still based largely on observed symptomatologies, which are not so different from the positions of Bleuler and Kraepelin.

Therefore, clinicians and researchers have continued to propose stricter sub-nosological distinctions within the broadening schizophrenia phenotype, to include subclasses like schizoaffective disorder [28], process-non process schizophrenia [29], schizophreniform psychoses [30] and paranoid-non paranoid schizophrenia [31]. Five types of schizophrenia were initially defined and used to reach a diagnosis (disorganized, paranoid, catatonic, residual, and undifferentiated); however, researchers began advocating the use of other classification systems that would be based on the prevalence of positive or negative symptoms, progression of disease, and the presence of co-morbidities [17].

In the 1950s, Kurt Schneider [32] described a set of core features designated as "first-rank" symptoms which include, hearing one's thoughts spoken aloud, auditory thoughts or hallucinations, thought withdrawal, insertion and broadcasting, somatic hallucinations, delusional perceptions, or the experience of one's thoughts as being controlled or influenced by outside; believing that these symptoms carried enough weight to decisively aid clinicians in the universal diagnosis of schizophrenia [17, 19]. The Schneiderian symptom ranking system, although criticised as either being non-specific or being deficient in its ability to predict severe deterioration and cognitive deficit [33], has been incorporated into a number of clinical diagnostic classification systems like the Research Diagnostic Criteria (RDC), Diagnostic and Statistical Manual of Mental Disorders (DSM) and the International Classification of Diseases (ICD).
In 1999, Karl Leonhard [34] proposed and developed a classification of "endogenous" psychoses, a significant departure from the previously accepted (Kraepelinian and Bleulerian) nosology. Leonhard's classification (Table 1) defined clearly-delineated entities based on the presence of a well-defined psychopathology that took into consideration objective signs like psychomotor behaviour, disease course, outcome, and family history. Leonhard's classification foreshadowed newer theories that proposed that schizophrenia be considered as more of a disease spectrum [35] than a single disease entity. This notion opened the door to broader classifications and subtypes of schizophrenia by researchers like Rado [36], Meehl [37], Chapman and Chapman [38]; and evolved to include the incorporation of schizotypal personality disorder (SPD) in the DSM-III diagnostic category.

To date, a diagnosis of schizophrenia relies on criteria outlined by either the ICD-10 [39] or the DSM 5 [40]. The ICD-10 uses both Kraepelinian and Schneiderian concepts in schizophrenia diagnosis, while the DSM-5 is based largely on reported abnormalities in behaviour, self-reported experiences of the patient, a clinical assessment by a certified mental health professional and evidence of symptom severity and/or impairment of activities of daily living. However, the classification /reclassification of schizophrenia [41-44], the defining/ redefining of criteria needed to make a diagnosis of schizophrenia $[45,46]$ and inclusion criteria for newer forms of schizophrenia [47, 48] would continue to evolve as newer insights and better understanding challenge the validity of the classic subtypes [49] as we know them now.

Table 1. Karl Leonhard's classification of the non-affective endogenous psychoses [19, 34]

I. Group of systematic schizophrenias (Insidious onset, auditory and somatic hallucinations, delusions, early blunting of affect, continuous unremitting course, personality deterioration)

(a) Paraphrenias (Auditory hallucinosis, audible thoughts, thought broadcast, passivity experiences, delusional misidentifications, falsifications of memory)

(b) Hebephrenias (Extreme autistic withdrawal, flat affect, impoverished or disorganized speech and behaviour)

(c) Catatonias (Excessive parakinesias, mannerisms, verbigeration, posturing, stereotypies, mutism, auditory hallucinations)

II. Group of unsystematic (atypical) schizophrenias (Rapid onset, relatively preserved affect, remitting course, mild personality deterioration)

(a) Affect-laden paraphrenia (Paranoid delusions with affective loading)

(b) Cataphasia (schizophasia) (Incoherent, pressured speech but well-organised behaviour)

(c) Periodic catatonia (Episodic hyper- or hypokinesia, mixed excitatory and hallucinatory symptoms)

III. Group of cycloid psychoses (Sudden onset, pervasive delusional mood, multimodal hallucinations, labile affect, polarity of manifestations, typically complete recovery from episode)

(a) Anxiety-happiness psychosis (Extreme shifts of affect, polarity intense fear - ecstatic elation)

(b) Motility psychosis (Impulsive hypermotility - psychomotor inhibition)

(c) Confusion psychosis (Incoherent pressure of speech - mutism) 


\section{The Aetiopathogenesis of Schizophrenia}

The high individual and societal burden [50-52] of schizophrenia makes the discovery of better, more efficient and/or effective diagnosis, treatment and preventive interventions imperative. However, progress has been hampered by the lack of clearly-defined aetiologies. A number of aetiological theories have been proposed in an attempt to explain the possible mechanisms involved in the development of schizophrenia; also, the various dysfunctions that have been associated with schizophrenia include: neurodegeneration [53], neurodevelopmental abnormalities [4, 11], infection/inflammation [1, 54], immune and/or autoimmune dysfunctions $[55,56]$.

Over the years, researchers have considered the associations involving genetics $[57,58]$, environment $[6$, 59] and/or events surrounding brain development [4, 11]; although, recent scientific evidence considers schizophrenia as a heterogeneous syndrome. At the same time, an increasing number of clinical, epidemiological, and experimental studies have continued to show links between schizophrenia, brain development, neurotransmitter-receptor interactions,

infection/inflammation [1] and oxidative stress [60].

Attempts at characterizing schizophrenia's heterogeneity with respect to symptomatology, premorbid functioning and disease severity have only been modestly-successful in advancing treatment. Therefore, several researchers have proposed that a re-evaluation of our thought processes as it relates to schizophrenia has become absolutely necessary, if we are to devise solutions to this clinical/scientific puzzle that has baffled scientists for more than a century $[61,62]$.

\subsection{Schizophrenia, Risk Factors}

Numerous risk factors have been implicated in the development of schizophrenia [3]: with studies showing that environmental factors like prenatal/perinatal complications, urbanisation, immigration status, exposure to stressors (all forms of physical and sexual abuse) and drug abuse (amphetamine, methamphetamine, cannabis and cocaine) predispose to its development. Also, results from family, twin and adoption studies have provided newer insights into the nature of the roles of genetics $[6,12$, 63. 64]; while the results of other studies have opened our eyes to the complexity of the associations between genetics and schizophrenia, and the challenges of translating this knowledge for therapeutic benefits [65-67]. 1 Genes like the neuregulin (NRG1) [69-70],

disrupted-in-schzophrenia-1 (DISC1) [71, 72], dystrobrevin binding protein 1 (DTNBP1) [73-75], nuclear receptor related 1 protein (NURR1) [76], D-amino acid oxidase and regulator of G protein signalling (RGS4) [64, 77] are some of the candidate susceptibility genes for schizophrenia. DISC1 is arguably the most-characterized schizophrenia susceptibility gene and was originally discovered in a Scottish family with a high prevalence of schizophrenia and psycho-affective disorders [71, 72]. Genetic linkage studies have implicated mutations in DISC1 as a risk factor for schizophrenia [72, 78], while the NURR1 plays an important role in the maintenance of the brain dopaminergic system [76]; with its involvement in schizophrenia evolving.

Presently, schizophrenia is a relatively common disease entity with relatively constant lifetime prevalence (1\%) worldwide. This implies that to maintain a stable global prevalence, the frequency of the causal factors must be constant, and the risk factors must also be common and ubiquitous [61]. Monozygotic twin studies have accorded only a $50 \%$ concordance rate for schizophrenia [79], also suggesting that for schizophrenia to develop, there must be at least two global risk-increasing categories, possibly genetic or environmental [61, 80]. Environmental factors like social isolation, maternal stress and immune activation have also been found to mimic or exacerbate symptoms of schizophrenia in genetically-modified rodents [80].

Evidences have continued to show the need to pay more attention to the immense impact of environmental exposures on the development of schizophrenia [59]; due to the availability of information from several birth cohort studies, extensive databases on prenatal and perinatal risk factors, and the improvement in the ability to measure environmental risk [59]. Epidemiological studies have demonstrated 1) an overall higher incidence in males, compared to age-matched females [46], 2) an increased risk among individuals living in urban, compared to rural areas [81, 82], with approximately $30 \%$ risk for developing of schizophrenia ascribed to birth in an urban environment $[83,84], 3)$ an increased incidence amongst migrant populations [85]. These epidemiological studies also reveal that triggers such as social disadvantage [86], pre-conceptional and prenatal exposure to genital or reproductive tract infections [59 87, 88], maternal respiratory tract infections [89], bacterial infection [90] and pyelonephritis [91] have all been associated with an increased risk of schizophrenia in the offspring. Maternal micronutrient deficiencies like retinoids, folate, vitamin D [92-95], iron, essential fatty acids and other nutritional deficiencies have also been associated with increased risk [96]; and so is maternal stress and anxiety [97]. In early childhood and adolescence, exposure to cannabis [98], psychoactive drugs like phencyclidine and amphetamines, low socioeconomic status [99] and childhood trauma [100] have all been associated with an increased risk. The importance of the environment in the aetiopathogenesis of schizophrenia is highlighted by preclinical studies that have reported the presence of schizophrenia-like phenotypes following environmental exposures to anxiety/stress [101], infections, psychoactive drugs, nutritional/micronutrients deficiencies [102] and 
malnutrition in the prenatal, early neonatal and adolescence periods; with putative biological mechanisms that implicate similar neuro-morphological and neurochemical substrates as observed in prior schizophrenia studies [103].

\section{Neurobiology of Schizophrenia}

Certain evolutionary theories have suggested that schizophrenia is a disorder that may have co-evolved with the evolution of the human brain [104]; stating that increases in energy demands that follow increase in the complexity and size of the human brain (relative to body mass) led to a greater demand of mitochondria. The use of post-mortem brain tissue to study the possible structural abnormalities associated with schizophrenia has long underpinned efforts to understand its neurobiology. However, the significant advances in the field of functional neuro-imaging (allowing real-time evaluation of changes in neurotransmitter metabolism, receptor density and neurotransmitter/receptor interactions) and improvement in immunohistochemical/immune-fluorescence staining techniques (that have enabled qualitative and quantitative examination of post-mortem brain tissue in both humans and rodents) have revolutionized our understanding of the neurobiology of schizophrenia. The roles of neurotransmitters, receptors and transporters in aetiology, as well as response to treatment, and other pharmacological manipulations have also been assessed; these sites are amenable to therapeutic manipulations, and in a number of cases, are the sites of drug action with proven antipsychotic activity [105].

Hypotheses that have implicated a number of neurotransmitter systems in the pathogenesis of schizophrenia have evolved from studies using drugs that target different neurotransmitters, receptors and transporters, to explain behavioural, biochemical and structural changes observed. Different markers have been used to demonstrate changes in some neurotransmitter (dopaminergic, serotonergic, cholinergic, glutamatergic and GABA) systems in the brain of schizophrenics [106]. A number of the changes observed are region-specific; and at times associated with alterations in levels or densities of non-neurotransmitter proteins like synaptosomal associated protein-25 (SNAP-25), syntaxin, synaptobrevin, synapsin, synaptotagmin, and synaptophysin, which are involved in all neurotransmitter systems, and are critical to neurotransmitter release [107]. Interactions between these specific proteins ensure fusion of synaptic vesicles with the synaptic membrane and subsequent release of neurotransmitter [108]. Genome-wide linkage studies for schizophrenia-susceptibility genes have reported significant linkage to the chromosomal region 20p12.3-11, which contains SNAP-25, suggesting that 20p12.3-11 is a strong candidate region for the disease [109]. Alterations in postsynaptic density complex proteins have also been reported in schizophrenia, and have been linked to deficits in synaptic plasticity and molecular processes that underlie cognitive functions [110].

\subsection{Neurotransmitter/ Receptor Dysfunctions in Schizophrenia}

There is extensive evidence implicating alterations in a number of neurotransmitter/receptor systems \{dopamine (DA), glutamate, serotonin (5-HT) and $\gamma$-amino butyric acid (GABA) $\}$ in the aetiopathogenesis of schizophrenia $[111,112]$. Theories and hypotheses have linked these neurotransmitter systems to a) risk of schizophrenia, b) symptomatology, c) disease progression d) response to therapy. The knowledge of these links have been employed in a number of preclinical studies, and have resulted in the development of validated pharmacologic and genetic disease models; which allow the replication of behavioural, neuro-developmental [11], neuro-morphological 113-116] and neurochemical phenotypes similar to those observed in humans [103]; and the investigation of novel therapies [117-122].

Early theories focused mainly on the involvement of the DAergic system, largely because the first successful therapies involved the use of DA antagonists. However, the development of more effective drugs such as clozapine shed more light on the possible involvement of other systems like the 5-HTergic, glutamatergic and GABA systems. More recently however, newer hypotheses address the interactions that exist between DA and 5-HT as well as the involvement of alpha-adrenergic, muscarinic, and histaminic receptors/ neurotransmitters in schizophrenia aetiopathogenesis.

In the early years of this century, growing concerns that alterations in brain functions modulated by the cholinergic system could result in schizophrenia-like behaviours led to the suggestion that changes in this system which modulates a number of central nervous system (CNS) functions (sensory perception, motor function, cognitive processing, memory, arousal, attention, sleep and psychosis) may be involved in the aetiology of the disease. This is coupled with the evidence of a high prevalence of nicotine (cigarette) usage in the population with schizophrenia [123], with nicotine-dependence linked to severity of symptom and poor outcome in schizophrenics; although the neurobiological mechanisms behind nicotine dependence in schizophrenia are still being studied [123] The involvement of muscarinic cholinergic receptors in schizophrenia is supported by evidence from post-mortem, neuropsycho-pharmacological and neuro-imaging studies [124]. Post-mortem studies have demonstrated a decrease in the number of cholinergic interneuron in the ventral striatum in schizophrenia [125], some early studies also observed a decrease in the level of muscarinic receptor binding in the frontal cortex of schizophrenics compared to healthy subjects [126]. A number of these studies observed 
that decreases in muscarinic receptor density in schizophrenia was disease-specific, with evidence demonstrating that these effects were not observed in other mental disorders. They also reported that these alterations were also region and subtype-specific, involving in particular the muscarinic M1-receptor subtypes [124]. Neuropharmacological studies have also demonstrated the efficacy of anti-cholinergics in the modest alleviation of negative symptoms, although worsening psychosis [127]; effects that have been attributed to an increase in dopamine release that follow anticholinergic use [128]. Anticholinergics have also been used to treat the motor side-effects of other antipsychotics.

\subsection{Schizophrenia: Hypotheses and Theories}

\subsubsection{Dopamine Hypothesis}

Dopamine (DA) is a major neurotransmitter with strong connections that serve to link different areas of the brain. These dopaminergic pathways are projection neurons that synthesise and release dopamine. The three main DAergic projections are the nigrostriatal (motor control), the mesolimbic/mesocortical (emotion and drug-induced reward mechanisms), and the tuberohypophyseal projections, which run from the hypothalamus to the pituitary gland. The DAergic receptors are G-protein-coupled receptors which are divided into the $\mathrm{D}_{1}$ family $\left(D_{1}\right.$ and $\left.D_{5}\right)$ and the $D_{2}$ family $\left(D_{2}, D_{3}\right.$ and $\left.D_{4}\right)$.

Initial evidences linking dopamine dysfunction to schizophrenia were indirect, being derived from observations that amphetamine (which increases brain levels of dopamine) worsens psychotic symptoms and drugs like reserpine (that depletes vesicular stores of monoamines; hence reducing brain levels of DA) reduce psychotic symptoms [129]. As far back as the 1960s and 70s, the following facts were known: a) DA receptor blockade was involved in the alleviation of psychosis by phenothiazines and butyrophenones and, b) increased DA and/or norepinephrine activity exacerbates symptoms of schizophrenia [130, 131]. More recently however, biochemical studies in schizophrenics have revealed increased cerebrospinal and plasma levels of DA metabolite; and subsequent molecular imaging and post-mortem studies have provided evidence for alterations in brain DAergic function in schizophrenics [132].

The DA hypothesis states that antipsychotics reduce psychotic symptoms by decreasing DA activity. This hypothesis (with its revisions) eventually became one of the most enduring theories in psychiatry [111]. It had its origins first in the discovery of antipsychotic drugs, the seminal work of Carlsson and Lindquit [133], Carlsson and co-workers [134] and later Seeman et al., [135]; who at different times demonstrated a relationship between available antipsychotic drugs, their ability to increase DA metabolism, and later their interactions at DA receptors. In its unrevised version, the DA theory attributes the pathophysiology of schizophrenia to an excess activity of the neurotransmitter DA. The excess DA activity could either be presynaptic (excess production) or postsynaptic (increased $\mathrm{D}_{2}$ receptor density or increased postreceptor action). However, this initial version of the theory could only account for the positive symptoms [136]; also, it could not articulate its relationship to genetics, neuro-developmental deficits, or other known risk factors of schizophrenia at the time, and it did not have any framework linking the dopaminergic abnormality to symptomatology [111].

The second version of the DA theory [137] challenged the hyperdopaminergic neurotransmission proposal of the initial version and brought to light the regional (cortical-subcortical) specificity of DA receptor distribution and interactions. This version suggests that an imbalance between excessive stimulation of $\mathrm{D}_{2}$ receptors in subcortical regions and an under-activation of $\mathrm{D}_{1}$ receptors in cortical regions may account for the presence of positive and negative symptoms [138]. So far, significant strides in investigational capacity have not only increased our knowledge base, it had also afforded the use of functional imaging (positron emission tomography and single photon emission computerized tomography) in examining the relationship between schizophrenia, DA receptor and/or brain DA levels. From these, it was deduced that schizophrenia is associated with; a) demonstrable elevations of presynaptic striatal DA synthesis [139], b) increased striatal DA release following an amphetamine challenge [140], c) evidence of increased baseline DA receptor occupancy following application of a DA depletion technique [141], d) a region- specific increase in striatal $\mathrm{D}_{2} / 3$ receptor density which is independent of the effects of antipsychotic therapy [142], and e) presence of cognitive impairment and/or negative symptoms that correlate with $\mathrm{D}_{1}$ receptor dysfunction [143, 144].

Genome-wide studies have also demonstrated the possible relationship that could exist between DA and heredity, with 4 of the top 10 gene variants most strongly associated with schizophrenia discovered to have direct involvement with DAergic pathways. The vesicular monoamine transporter protein gene variant has been reported to have one of the strongest associations to the DAergic system; the protein induces the accumulation of DA and other monoamines within vesicles. Other gene variants like the genes for methylene-tetrahydrofolate reductase have an indirect effect on the DAergic system [145]. The role of environmental factors in the development of schizophrenia has also been buttressed by results from animal studies that have demonstrated the presence of long-term mesostriatal DAergic overactivity following exposure to pre- and perinatal factors [146], with prenatal stress or neonatal lesions of the hippocampus and frontal cortex increasing DA-mediated behavioural responses in rats. 
Overall, DAergic disruption in schizophrenia is considered a final common pathway in the complex interactions between genes and the environment, resulting in presynaptic striatal hyperdopaminergia [146, 147], which may be secondary to pathophysiological changes in other neurotransmitter systems (e.g. pre-frontal glutamatergic or GABAergic systems). There have also been suggestions that prior NMDA receptor hypofunction and low-grade inflammation of the brain might predate increased dopamine synthesis [147].

\subsubsection{Serotonin Hypothesis/ Serotonin-dopamine Hypothesis}

Wooley and Shaw [148], and Gaddum and Hammed [149] were among the first set of researchers to consider the involvement of serotonin (5-HT) in schizophrenia; based on the psychotomimetic effects observed with lysergic acid diethylamide (LSD) and its antagonists, at brain 5-HT receptors. In 1962, Wooley published what can be considered a 'prophesy' on 5-HT's relationship with schizophrenia [150]. These scientists believed that 5-HTergic activity might be decreased in schizophrenia; although this was faulted because of striking differences like, 1) the behavioural phenotypes observed with LSD intoxication did not include any of the major symptoms that were characteristic of schizophrenia [151], 2.) LSD was also associated with visual hallucinations which were believed to be rarely observed in schizophrenia [152]. However, more recent studies have demonstrated that the behavioural symptoms associated with the use of hallucinogens share common phenomenological similarities with the acute phase of schizophrenia [153]. Also, the prevalence of visual hallucinations in schizophrenia may be more frequent than commonly believed [154], with studies showing increased incidence during the acute phase of schizophrenia [155].

Another confounding factor was that classical hallucinogens like LSD were full or partial agonists at many 5-HT receptors $[151,156]$ and 5-HT antagonists like cyproheptadine and ritanserin did not have psychomimetic effects. The overall effects of these was a decline of interest in the 5-HT-deficiency hypothesis, followed by decades of limited consideration of the role of 5-HT in schizophrenia [157]; although a few biochemical studies assessing the regional density of specific types of 5-HT receptors in the brain reported findings which continued to suggest the presence of some form of serotonergic dysfunction in schizophrenia [157]. Renewed interests in the validity of the 5-HT hypothesis began with the identification of a number of 5-HT receptor subtypes and their extensive impact on multiple neurotransmitters, the realisation that the effectiveness of clozapine in improving schizophrenic symptoms (with fewer side-effects than typical antipsychotics) could be attributed largely to its ability to block $5-\mathrm{HT}_{2 \mathrm{~A}}$ receptors [158], and suggestions of the existence of associations between 5-HT and DA. Evidence from a number of studies have implicated 5-HT in the development of deficits in early information-processing that is associated with alteration in cognitive processes such as memory, sensory gating, perception and attention, aggressive behaviours, appetite and pain sensitivity [159]; functions that are important in the development of cognitive impairments, and positive/negative symptoms which constitute the core abnormalities of schizophrenia $[155,157]$. Studies also demonstrated that these deficits observed in schizophrenia [160] were also observed in rodents and humans who had received serotonin agonists [161].

Results of biochemical and anatomical studies demonstrating the extensive interactions of the 5-HTergic system with multiple neurotransmitters (DA, glutamate and GABA) provided evidence for the ability of 5-HT to influence behaviours [157]. The first clear statements relating to 5-HT emerged following suggestions that the positive symptoms experienced in schizophrenia could occur from enhanced DAergic and 5-HTergic neurotransmission in sub-cortical areas, while decreased DAergic and 5-HTergic activity in the prefrontal cortex may be associated with negative symptoms [162].

The 5-HT hypothesis was boosted by studies in humans [163] and rodents [164] that demonstrated that LSD or psilocybin produced psychomimetic effects mimicking schizophrenia-like behaviours through excessive activation of 5- $\mathrm{HT}_{2 \mathrm{~A}}$-receptor, and the demonstration of region-specific alteration in $5-\mathrm{HT}_{2}$-receptor density in the brains of schizophrenic patients [165]. Pharmacologic manipulation of the 5-HTergic system have also been shown to exacerbate or mitigate schizophrenic symptoms (positive, negative or disorganization) and cognitive function, as well as modulate drug-related side effects of DA antagonists such as extrapyramidal symptoms, tardive dyskinesia and dystonia.

In examining the extent of involvement of 5-HT in the aetiopathogenesis of schizophrenia, a number of studies have been conducted to assess the ability of 5-HTergic agonists or antagonists to either exacerbate or ameliorate the symptoms that are associated with schizophrenia; with a large number of 5- $\mathrm{HT}_{2 \mathrm{~A}}$ receptor antagonists ameliorating these symptoms with minimal motor side-effects [166]. Also, both direct and indirect 5-HT agonists such as fenfluramine, $m$-chlorophenylpiperazine, tryptophan and 5-hydroxytryptophan were observed to worsen these symptoms [167]. A number of human studies have also demonstrated alterations in blood and cerebrospinal fluid levels of 5-HT and its metabolites, as well as hormonal and behavioural changes in response to 5HT-based therapies [157]. Alterations in 5-HTergic neurotransmission and receptor density in post-mortem brain specimens have also been reported; with a number of studies reporting a decrease in the density of prefrontal cortex $5 \mathrm{HT}_{2 \mathrm{~A}}$ receptors in schizophrenia [168], changes that have been associated more with the pathology of the disease than an effect of drug therapy during life. There are also studies that have demonstrated that in the planum 
temporal (the cortical area just posterior to the auditory cortex), changes in density of $5 \mathrm{HT}_{2 \mathrm{~A}}$ receptors observed have been associated with both pathological and antipsychotic drug effects [105]. Critics of the 5-HT hypothesis have suggested that a link between $5 \mathrm{HT}_{2 \mathrm{~A}}$ receptor and specific gene mutations is necessary if it was to be accepted that 5-HT receptors were central to schizophrenia aetiopathogenesis; and there have been studies that have reported mutations in the gene for the $5 \mathrm{HT}_{2 \mathrm{~A}}$ receptor using peripheral tissue DNA from schizophrenic patients [169]. There was however no observed gene mutations or alterations in receptor density in post-mortem brain tissue $[170,171]$.

\subsubsection{Glutamatergic Theory}

As first put forward by Olney and Farber [172], the N-methyl-D-aspartate (NMDA) receptor dysfunction hypothesis of schizophrenia is a theory that stemmed from the observation that non-competitive NMDA receptor antagonists, like phencyclidine (PCP), dizocilpine (MK-801) and ketamine have central effects which closely resemble positive and negative symptoms of schizophrenia $[173,174]$. Chronic ketamine users also exhibit psychotic-like symptoms [175]. The above findings led to the use of NMDA receptor antagonists in the modelling of schizophrenia. Olney and Farber [172] also showed that administration of NMDA receptor antagonists in animals led to development of neurotoxic changes and volume changes in cortical brain regions, which were similar to those seen in patients with schizophrenia [172]. They also discovered that

$\alpha$-amino-3-hydroxy-5-methyl-4-isoxazolepropionic acid (AMPA) antagonists could block the downstream effects of NMDA receptor antagonism on neurotoxicity, and went on to hypothesise that glutamate release probably underlies the neurotoxic effects; a position that was subsequently confirmed by microdialysis studies [176] and proton magnetic resonance spectroscopy (1H-MRS) studies using animals that were administered ketamine [177]. NMDA antagonists like ketamine and PCP have been used to model both acute and chronic forms of schizophrenia in rodents, depending on the administration regimen; however, the regimen that employs repeated administration is known to mimic both behavioural and brain structural changes that are seen in schizophrenics [178-180]. Subchronic administration of PCP to rats was shown to cause long-lasting deficits in set-shifting ability [180] and reductions in functional connectivity [179]; while longer term administration of ketamine to rats caused cognitive deficits [181]. Hence, repeated administration of NMDA antagonists in rodents has been associated with brain behavioural and structural changes that closely resemble clinical schizophrenia.

\subsubsection{The two-hit Hypothesis and the Neurodevelopmental Theory}

In an attempt to account for the complex and intricate involvement of genetics, environment, developmental biology, and the late adolescent/early adulthood onset of schizophrenia; the "two-hit" hypothesis was considered. It is based on assumptions that genetic or environmental factors disrupt early CNS development; with these disruptions resulting in long-term vulnerability to a "second hit" which then leads to the onset of schizophrenia symptoms [182]. The numerous cell-cell signalling pathways that exist at the different stages of morphogenesis and differentiation (in the brain) could be targets for a "first hit" which may then predispose the CNS to a pathologic response of a "second hit", either through the same or other related signalling pathways [13]. Proponents of this hypothesis are of the opinion that neither the first or second insult by itself is enough to induce schizophrenia [182].

Predating the two hit hypothesis is the neurodevelopmental hypothesis which suggests that schizophrenia is a neurodevelopmental disorder affecting young adolescents, the aetiology of which may involve pathologic processes that involve genetic and environmental disruptions occurring during brain development [183, 184], for a more detailed review on the neurodevelopmental theory of schizophrenia, see review by Fatemi and Folsom, [184] and Rapoport et al. [183]. There is ample evidence linking neurodevelopmental abnormalities occurring as early as the late first or early second trimester or thereafter, to a predisposition to the development of schizophrenia in adolescence [184]. The "two-hit" model proposed by Keshavan [185], and Keshavan and Hogarty [186] was able to link the neurodevelopmental hypothesis framework in which maldevelopment at two critical periods of brain development (early brain development and adolescence) interact to produce the symptoms associated with schizophrenia. This model accounted for presence of premorbid symptoms (which may be due to the early developmental insults leading to disruption of specific neural networks) that have been observed to predate the development of the full-blown schizophrenia symptoms; while excessive dysfunction of synapses and loss of brain plasticity at adolescence may then account for the emergence of schizophrenia $[185,186]$.

More recently however, the opinion that the development of schizophrenia is likely more complex than can be explained by the two-hit hypothesis continues to gain popularity. This is buttressed by emerging evidence of very complex processes involving genetic risk interfacing with multiple potentially-interacting hits and vulnerability factors occurring at key periods of neurodevelopment, culminating in the expression of the disease state [187].

\subsubsection{Inflammation and the Immunologic Theory of Schizophrenia}

Cytokines and the immune system have been discovered to influence and modulate behaviour and the development of the CNS [188]. Reports from studies investigating the 
possible influence of prenatal immune activation $[189,190]$ on the development of schizophrenia, and the discovery of susceptibility genes which have regions that are related to immune function [191] have reawakened interests in the immunologic theory and the autoimmune theory of schizophrenia [54, 192]. Early studies reported alteration in immune function, coupled with the presence of antibodies targeted against CNS tissue in schizophrenics [56]; while imaging studies have demonstrated increased inflammation [54, 193] in schizophrenics. Initial studies evaluating the mechanisms of cytokine involvement in schizophrenia were of the opinion that a shift away from a T-helper-1 response towards a T-helper-2 response [194] was responsible for this disorder. However, more recent biomarker studies have revealed mixed response (type 1 and type 2) alteration in cytokine activity involving Interleukin-2 (IL-2), Interferon-gamma (IFN- $\gamma$ ), Tumour Necrosis Factor alpha (TNF- $\alpha$ ) which are type 1 responses; and type 2 responses like IL-4 and IL-13 [195], for a more detailed review on the role of inflammation in schizophrenia see Feigenson et al. [1].

\section{Pharmacotherapy Past, Present and Future}

Today, schizophrenia is viewed as a heterogeneous entity associated with separate genotypic networks that manifest as several distinct clinical syndromes [196, 197]; along this line, a poor response to certain drugs might be as a result of an encounter with a distinct subtype of schizophrenia, and not necessarily a manifestation of the 'severity' of illness [198]. In 2014, Howes and Kapur [199] proposed the neurobiological classification of schizophrenia (to be used in determining treatment options) into type A (hyperdopaminergic: characterised by elevated striatal dopamine synthesis and release capacity) and type B (normodopaminergic: characterised by an absence of dopaminergic alterations); based on observations linking the development of psychotic symptoms to alterations in dopamine levels in the majority of patients with schizophrenia, and also emerging evidence demonstrating that this is not common to all patients [199]. Treatment options for schizophrenia have however continued to evolve.

Till the first half of the $20^{\text {th }}$ century, a lot of trial and error treatments (many of which were painful, bizarre and unsuccessful) for schizophrenia were being applied [17]. These treatments, sometimes called 'biological therapies' include fever therapy (induction of fevers by injecting sulphur and oil, or causing abscesses), gas therapy, electroconvulsive therapy, frontal lobotomy, simple sedation, deep insulin coma, lobectomy/leucotomy, and so on $[17,200]$. Many of these 'treatments' are fanciful but ineffective, and dangerous by today's standard; but they were applied in an era when there was a lack of understanding of the neurochemical basis of the disorder.
In the 1950s, relatively-specific pharmacotherapy came by way of the discovery that chlorpromazine was effective in curbing agitation in psychotic patients [201]. The advent of chlorpromazine marked the beginning of the "psychopharmacological era' [202] as it became the first effective antipsychotic drug; and was later followed by the synthesis of haloperidol in 1958 [202]. Clozapine was synthesised in 1958, and by 1966, human trials confirmed that clozapine was an effective antipsychotic with no disabling neurological side-effects. Currently, antipsychotic agents in use can be put under three generations. First generation: dopamine antagonists (low potency drugs e.g. chlorpromazine; high potency drugs e.g. pimozide, haloperidol, fluphenazine); second generation: dopamine-serotonin antagonists (risperidone, paliperidone) and multitargeted antipsychotics (clozapine, olanzapine, ziprasidone, quetiapine, asenapine, iloperidone); third generation: dopamine-functionally selective (aripirazole, brexpiprazole, cariprazine) [200]. These classifications also give some clues regarding the neurotransmitter receptors that the drugs interact with. The first generation drugs interact primarily at dopamine $\mathrm{D}_{2}$ receptor; the second generation drugs act at multiple receptor sites, including $\mathrm{D}_{1}, \mathrm{D}_{2}, \mathrm{D}_{3}$, and $\mathrm{D}_{4}$, adrenergic (alphal and alpha2), serotonin $\left(5 \mathrm{HT}_{2 \mathrm{~A}}\right.$ and $\left.5 \mathrm{HT}_{2 \mathrm{C}}\right)$, histamine and muscarinic receptors. Third generation drugs are considered as functionally-selective/partial $\mathrm{D}_{2}$ agonists ("DA-stabilisers") with possible actions on $5-\mathrm{HT}_{1 \mathrm{~A}}$ and 5- $\mathrm{HT}_{2 \mathrm{~A}}$ sites.

\subsection{Linking Aetiological Theories to Pharmacotherapy of Schizophrenia}

\subsubsection{Dopamine-based Therapy and First Generation Antipsychotics}

DA-based therapies have continued to play a central role in the management of schizophrenia [203]. Chlorpromazine replaced surgical and electroconvulsive therapies, and this was heralded as a significant turning point in the field of psychiatry [203]. First generation antipsychotics act at the dopamine $\mathrm{D}_{2}$ receptor and produce effects by its blockade. The first generation antipsychotics (also called typical or classic antipsychotics) include drugs in the following sub-classses: phenothiazines, butyrophenones, thioxanthenes, dibenzoxazepines, dihydroindoles, and diphenylbutylpiperidines. They are believed to act via postsynaptic blockade of brain dopamine $\mathrm{D}_{2}$ receptors; and evidences supporting this include strong antagonism at $\mathrm{D}_{2}$ receptors in both cortical and striatal areas, a high correlation between $\mathrm{D}_{2}$ receptor-binding and clinical potency, and also, a consistent requirement of $65 \% \mathrm{D}_{2}$ receptor occupancy for antipsychotic efficacy in functional imaging studies [175, $204,205]$. In the brain, their binding is not region-specific; hence, their ability to block DA receptors in the mesolimbic DA system is responsible for the amelioration of positive symptoms [206], while their effects at 
mesocortical, nigrostriatal and tuberoinfundibular DA receptors are believed to account for the Parkinson's-like symptoms (muscle rigidity, tremors, tardive dyskinesia) and hyperprolactinemia that tend to be associated with their use [207]. Their binding is also not receptor-specific (with individual drugs showing distinct activities at $5-\mathrm{HT}_{2 \mathrm{~A}}$, alpha-1, histaminic, and muscarinic receptors; accounting for further side-effects). First generation drugs are also ranked as either high- or low-potency drugs. The high-potency drugs (fluphenazine, haloperidol, loxapine, perphenazine, pimozide, thiothixene, and trifluoperazine) are associated with little sedation, weight gain, or anticholinergic activity, but a high risk for extrapyramidal side-effects; while the low-potency drugs (chlorpromazine and thioridazine) require higher doses, have high histaminic and muscarinic activity (and anticholinergic effects), but reduced occurrence of extrapyramidal side-effects. Generally, these drugs are only partially-effective or ineffective in certain subsets of patients. However, despite the limitations associated with their use, they have continued to play an important role in the management of schizophrenia [208].

Second-generation antipsychotics (atypical antipsychotics) were approved in the late 1980s, with the belief that they were more effective at treating symptoms of schizophrenia with minimal extrapyramidal side-effects [207]; however, like typical antipsychotics, the atypical drugs also bind to dopamine $\mathrm{D}_{2}$ receptors, although with lesser affinity. Atypical antipsychotics also show an affinity for the serotonin-2A $\left(5-\mathrm{HT}_{2 \mathrm{~A}}\right)$ receptor [138]; and the ratio of $5-\mathrm{HT}_{2 \mathrm{~A}}$ to dopamine $\mathrm{D}_{2}$ receptor affinity separates typical from atypical antipsychotic drugs.

\subsubsection{Limitations of the Dopamine-based Treatment}

About one-third of schizophrenics do not respond to non-clozapine antipsychotics [209], or manipulations that are based on $\mathrm{D}_{2}$ receptor occupancy or depletion of presynaptic dopamine [210]. Hence, for a significant number of schizophrenics, the pathophysiological basis of their symptoms involves more than DAergic excess, or may be unrelated to dopaminergic dysfunction. Also, it appears that patients who are likely to respond to dopamine-based drugs tend to show a raised dopamine synthesis capacity [141, 211]; so, from the afore-going, the suggestion of the existence of a 'non-dopaminergic' sub-type of schizophrenia seems logical [199]. Dopaminergic dysfunction is linked to both negative and cognitive symptoms of schizophrenia [129]; however, in clinical practice, DA antagonists and partial agonists only have modest to no effects on cognitive impairments and negative symptoms [212], or they may worsen cognitive function [213].

\subsubsection{Serotonin Based Therapies}

\subsubsection{Serotonin Antagonists: Second Generation Antipsychotics}

Clozapine was the first antipsychotic agent that showed efficacy in the management of treatment-refractory schizophrenia [207]. Atypical antipsychotics are classically defined as drugs in which there is a marked dissociation between doses that inhibit amphetamine-induced stereotypy and those that result in catalepsy; implying a dissociation between the antipsychotic effect and the presence of extrapyramidal symptoms (EPS). Clozapine has a very high affinity for $5-\mathrm{HT}_{2 \mathrm{~A}}, 5-\mathrm{HT}_{2 \mathrm{C}}, 5-\mathrm{HT}_{6}$, and $5-\mathrm{HT}_{7}$ receptors, and the use of clozapine is also devoid of EPS; which are abnormalities of muscle tone and movement that may be serious enough to warrant extra therapy, or lead to discontinuation of a drug. The advent of clozapine corrected the erroneous impression that for a drug to have antipsychotic potential, it must be able to induce EPS experimentally. Second generation antipsychotics are devoid of EPS because the location of $5-\mathrm{HT}_{2 \mathrm{~A}}$ receptors presynaptically on DA terminals in the nigrostriatal and mesocortical pathways allows the augmentation of dopamine release which counteracts the effects of $\mathrm{D}_{2}$ antagonism (resulting in fewer extrapyramidal side-effects). These antipsychotics also ameliorate positive symptoms by their ability to transiently occupy and dissociate from $\mathrm{D}_{2}$ receptors, allowing DA neurotransmission [204, 214 215]. The efficacy of 5HT antagonists also lies in the expression of $5-\mathrm{HT}_{2 \mathrm{~A}}$ receptors throughout the cortex, where they contribute to the effects of atypical antipsychotics in improving cognition and affective symptoms, reducing negative thoughts and suicidal ideation [216], benefits not commonly observed with first generation antipsychotics [217, 218]. Although, atypical antipsychotics result in fewer EPS, they are however associated with a number of metabolic side-effects like glucose intolerance and weight gain [219]. Today, second and third-generation antipsychotics e.g. olanzapine, risperidone, quetiapine, ziprasidone and aripiprazole have become the mainstay of the treatment of schizophrenia; however, cost is a major factor, especially in low-income countries where first generation drugs remain a valuable option in the treatment of psychotic disorders [208]. Also, data showing their superior efficacy (relative to first generation drugs) have been inconsistent [220], except clozapine in treatment-resistant patients. A major point in favour of second generation drugs is a lesser tendency to be associated with EPS. For the first generation drugs, both therapeutic (antipsychotic) effect and side-effects (EPS) are related to $\mathrm{D}_{2}$ receptor occupancy [221]; therefore, side-effects are a direct extension of desired effects. Second-generation drugs exert their therapeutic effects through $\mathrm{D}_{2}$ antagonism (to some extent), but mainly through blockade of $5 \mathrm{HT}$ (mainly $5 \mathrm{HT}_{2 \mathrm{~A}}$ ) receptors. $\mathrm{D}_{2}$ receptor affinity is a strong measure of the antipsychotic efficacy of first generation, but not second generation drugs; in fact, clozapine (which is the most effective) also has the lowest $\mathrm{D}_{2}$ affinity. Risperidone and olanzapine, both of which have high $5-\mathrm{HT}_{2 \mathrm{~A}}$ receptor blocking activity relative to their $\mathrm{D}_{2}$ affinity [222] also show greater efficiency for treating negative symptoms of 
schizophrenia. Second generation drugs also differ in their binding to $\mathrm{D}_{2}$ receptors [223]. However, a number of studies have shown that second generation drugs do not have significantly superior tolerability compared to typical antipsychotics; and even though they generally cause less EPS, there are still considerable variations within the class [224]. Presently, however, they are still recommended by current guidelines as the first-line therapy in the treatment of schizophrenia [225].

\subsubsection{Selective Serotonin Re-uptake Inhibitors}

The continued administration of selective serotonin reuptake inhibitor (SSRI) has been observed to increase serotonergic activity through the inhibition of 5-HT uptake and desensitization of the 5-HT autoreceptor, leading to increased 5-HT release. Goff et al. [226] reported that the addition of fluoxetine to typical antipsychotics in nine treatment-resistant patients improved positive and negative symptoms. Fluoxetine also alters postsynaptic receptor dynamics, resulting in increased responsiveness to $5-\mathrm{HT}_{1 \mathrm{~A}}$ agonists, and enhanced cortical release of DA with clinical evidence of improvements in negative symptoms, when added to depot neuroleptic [226]. In an era where individualised treatment for schizophrenia is enjoying a strong advocacy, the indications for application of SSRIs may be at the brink of a renaissance. Some studies using animal models are beginning to suggest that for schizophrenia management in certain subsets of patients, drugs such as SSRIs may be considered as the mainstay, instead of being an adjuvant. In a recent study, Onaolapo et al. [120] showed that in a mouse model of ketamine-induced schizophrenia, sertraline administration alone led to significant attenuation of ketamine-associated behavioural changes. The improvement in symptoms due to administration of these drugs may be due to either enhancement of serotonergic or mesocortical/mesolimbic activity, or both.

\subsubsection{Serotonin Receptor Agonist}

The $5-\mathrm{HT}_{1 \mathrm{~A}}$ receptor is a subtype of serotonin receptor which is can be presynaptic and/or postsynaptic. The activation of this receptor has been associated with the anxiolytic, antidepressant and antipsychotic activities of some medications. There are suggestions that $5-\mathrm{HT}_{1 \mathrm{~A}}$ receptor agonists may have antipsychotic-like properties [227], and also be effective in reducing antipsychotic-induced EPS [228]. Ziprasidone, one of the new atypical antipsychotic drugs, is a potent $5-\mathrm{HT}_{1 \mathrm{~A}}$ agonist, while clozapine is a partial agonist at the $5-\mathrm{HT}_{1 \mathrm{~A}}$ receptor. Buspirone is another partial 5- $\mathrm{HT}_{1 \mathrm{~A}}$ agonist with mixed reports (improve, or have no effect) on positive and negative symptoms in schizophrenic patients receiving typical antipsychotics. It has also been shown to be beneficial on EPS and akathisia [229]. Therefore, apart from their benefits in reducing EPS, the role of $5-\mathrm{HT}_{1 \mathrm{~A}}$ receptor agonists in the management schizophrenia needs to be further studied.

\subsubsection{Glutamate-based Therapies}

Effects of NMDA receptor antagonists on brain structure and function lend supportive evidences to the glutamatergic transmission dysfunction hypothesis of schizophrenia. Also, the role of NMDA receptor hypofunction in the aetiology of schizophrenia has been supported by drug trials that demonstrated the benefits of glutamatergic agents in schizophrenia management [230]. According to earlier postulations (which were later validated through microdialysis studies), NMDA receptor antagonism can lead to increased cortical glutamate release and excitotoxicity, via reduction in the inhibitory tone of GABAergic interneurons that express NMDA receptors $[172,231]$. Studies have investigated drugs that modulate NMDA receptor through direct agonism at the glycine modulatory site (e.g. glycine or D-serine), or through increasing synaptic glycine levels by inhibiting glycine transporters (e.g. sarcosine). While it is believed that modulation of the glycine site may hold promise in the drug therapy of schizophrenia; the degree of derivable benefits from such manipulation is still being investigated. A meta-analysis of published studies suggested that when administered in addition to existing antipsychotic treatment, NMDA receptor modulators led to a significant improvement in residual positive and negative symptoms in patients with schizophrenia [232]. However, the outcome of a large clinical trial using D-serine, found the drug of no benefit in the management of schizophrenia [233]. Other glutamate-based medications include the glycine transporter inhibitor Bitopertin, which had in an initial trial had shown promise in the management of negative symptoms [234], however, two recent phase III studies, concluded it has no benefit in the management of negative symptoms [235], while its effects on positive symptoms have so far being modest at best.

Other drugs whose mechanisms of action are linked to the glutamate pathway include minocycline, an antibiotic with neuroprotective properties; which in animal models has been shown to counter the effects of multiple NMDA antagonists [236]. An initial open label study [237] demonstrated significant improvements in both positive and negative symptoms; and in controlled studies, it was associated with clinically-significant benefits regarding negative symptoms [238]. However, its mechanism of action might also involve an inhibition of the formation of reactive oxygen species [239]. Preclinical studies had shown that sodium nitroprusside can abolish the behavioural effects of phencyclidine [240]; and its administration has been associated with improvements in schizophrenia symptoms [241], probably via a glutamatergic mechanism involving modulation of NMDA receptor activity [242]. LY-2140023 (developed by Eli Lilly \& Co) is a methionine amide prodrug of the orthosteric metabotropic glutamate receptor agonist 
LY-404039 [243]. LY-404039 (pomaglumetad methionil or LY-2140023 monohydrate) is an amino acid analog drug that shows high selectivity for the metabotropic glutamate receptor group II subtypes $\mathrm{mGluR}_{2}$ and $\mathrm{mGluR}_{3}$ [244]. LY-404039 is believed to act through modulation of glutamatergic activity, and reduction of presynaptic release of glutamate at synapses in limbic and forebrain areas. An initial study documented significant improvements in positive and negative symptoms in patients with chronic schizophrenia [245]; but phase II trial did not show any significant benefit over placebo [246]. Lamotrigine reduces glutamate release and has been reported to inhibit ketamine-induced psychosis-like behaviours in healthy volunteers [247]. It also inhibits ketamine-induced changes in brain function, as measured by fMRI [248]. Early clinical data had suggested a significant benefit in the subset of patients who respond only partially to clozapine treatment [249]; however, subsequent meta-analyses suggest that effects were relatively modest [250].Topiramate is an AMPA receptor antagonist anti-seizure agent that regulates effect of excess downstream glutamate; however, its AMPA antagonism only occurs at higher doses, and its inhibitory effects are probably more through enhancement of GABA transmission than glutamate regulation [251] It was shown to reduce the behavioural effects of MK-801 in rats [252]; and an initially- promising open trial [253] using topiramate augmentation in treatment-resistant schizophrenia was also replicated in a randomised controlled trial [250]. Current clinical evidence demonstrates small to moderate benefits in relation to symptom control with topiramate augmentation; also, evidence suggests that topiramate may be useful in the prevention of antipsychotic-induced weight gain [254].

\subsection{Repurposing of Old Drugs and Adjunctive Therapies in Schizophrenia Management}

The concept of drug-repurposing is not new to pharmacology in general, or schizophrenia management specifically. Modern day pharmacotherapy of schizophrenia started with a repurposed drug, as chlorpromazine was originally developed as an adjunct to anaesthesia. Lamotrigine, topiramate and minocycline that were mentioned earlier, are repurposed for the management of schizophrenia. Presently, repurposed drugs have a place as alternative or adjuvant treatment options for patients who continue to respond poorly to standard regimens [255]; or better still, in the application of the concept of individualised management, where drugs used are specifically-targeted at the symptom clusters exhibited by a patient. Different classes of drugs have been repurposed for schizophrenia treatment and they include; non steroidal anti-inflammatory agents, antiepileptics, tetra-cyclic antidepressants, antinarcoleptics, antioxidants and hormonals (for a detailed review on repurposed drugs, see Bumb et al. [25] or Lee and Kim [256].

\section{(a) Non steroidal anti-inflammatory agents}

Presently, it is known that inflammation probably plays an important role in schizophrenia [257]; and research had shown up-regulation of certain genes that regulate expression of pro-inflammatory proteins, leading to increase in enzymes such as TNF-alpha, IFN-alpha and IFN-gamma, as well as changes in myelination [258]. Neuroinflammation is known to trigger microglial activation, leading to the production of inflammatory cytokines, increased activity of phagocytotic cells/proteins, and disruptive changes in the blood-brain barrier [259]. In a randomised, placebo-controlled, double-blind trial using aspirin as adjuvant treatment [260]; there was a significantly larger reduction of PANSS (positive and negative syndrome scale) positive scores, but not PANSS negative scores and cognitive function (in comparison to placebo). However, celecoxib, a selective inhibitor ofcyclooxygenase-2(COX-2) showed no demonstrable benefit (in relation to measured clinical outcomes (including psychopathology, functional disability, and extrapyramidal side effects) when used as add-on treatment [183] in chronic schizophrenia; although Müller et al [261] reported significant improvement in symptoms when used as an adjunct in early schizophrenia. Evidence of COX-2 involvement in synaptic activity, memory consolidation, neurovascular coupling, long-term potentiation and depression [262] has however renewed interests in the possible role of COX-inhibitors in schizophrenia management; and according to the findings of a recent meta-analysis, adjunctive celecoxib outperformed placebo in relation to positive symptoms, negative symptoms, total and general psychopathology scores in first-episode patients; but not in chronic schizophrenics [263].

\section{(b) Antiepileptics, antidepressant and other CNS medications}

Sodium valproate, an anticonvulsant approved for use in the control of manic episodes in bipolar disorder [264] has in recent times become a frequently-prescribed mood-stabilizer in schizophrenics [265]; its use follow suggestions that its actions at voltage-gated ion channels and on the GABA system could modulate mesolimbic dopaminergic activity in schizophrenics. In an open-label study, the positive effects of valproate as an add-on to second-generation antipsychotics like olanzapine and risperidone in patients with severe schizophrenia [266] were demonstrated. However, there is yet to be an approved role for sodium valproate in the management of schizophrenia.

Memantine is used in the management of Alzheimer's disease; it acts on the glutamatergic system by blocking NMDA receptors. Studies conducted to ascertain the possible use of memantine monotherapy or add-on in the management of schizophrenia have generated mixed 
results [267-270]; Uribe et al. [267] reported that neonatal administration of memantine to adult rats exposed to early maternal deprivation reduced social interaction deficits, while Omranifard et al. [270] in a double blind, randomised control study concluded that add-on therapy of memantine in schizophrenics treated with atypical antipsychotics reduced positive/negative symptoms of schizophrenia, and general psychopathology. Kishi et al. [268] also concluded on the possible beneficial effects of memantine add-on treatment in the management of negative symptoms in schizophrenics.

The use of antidepressants as add-on therapy in the management of schizophrenia has been researched extensively, but inconclusively [271]; however, in general, add-on antidepressants were not observed to worsen psychosis. Administration of mirtazapine, a tetra-cyclic antidepressant was reported to show consistent improvement of negative and extra-pyramidal symptoms [272] with enhancement of neurocognition; although it did not show consistency in the alleviation of the core symptoms of schizophrenia [266]. In a meta-analysis of the efficacy of mirtazapine as add-on therapy, it was concluded that adding mirtazapine to treatment can improve negative symptoms in schizophrenia [273]. Addition of mianserin to typical antipsychotics may be of benefit to patients with chronic treatment-resistant schizophrenia who have an acute psychotic exacerbation [274]; co-administration of mianserin was also found to attenuate or reverse haloperidol-induced motor deficits [275].

Modafinil is a eugeroic drug that has diverse effects on numerous neurotransmitter systems such as DAergic, GABAergic, glutamatergic, noradrenergic, 5HTergic and histaminergic pathways; and also exerts additional influence on orexinergic pathways. In a 2004 trial, a four-week modafinil add-on therapy led to improvement of cognitive and positive symptoms of schizophrenia, without inducing severe side effects [276]. Other trials have also reported improvement of PANSS positive and negative scales [277], and improvement of clinical outcome measures [278]. Pramipexole, a synthetic non-ergot aminobenzothiazole dopamine $\left(\mathrm{D}_{2} / \mathrm{D}_{3}\right)$ receptor agonist used in the management of Parkinsonism has also been associated with improvement of PANSS positive and negative scales [279].

\section{(c) Antioxidants, hormonals, trace elements and immunomodulators}

The two-hit, neuroprogressive, neurodevelopmental, inflammation and immunologic hypotheses present accumulating evidences that implicate oxidative stress in the development of schizophrenia. Antioxidants are biomolecules that can mitigate oxidative stress and/or its consequences [60]. A number of studies [280-282] have evaluated the possible effects of substances or compounds with antioxidant potential on schizophrenia; with reports that adjunctive therapy with $\beta$-carotene, quinones, and vitamins $\mathrm{E}$ and $\mathrm{C}$ at the acute stages of schizophrenia may prevent further oxidative injury and the development of full-blown symptoms of schizophrenia. $\mathrm{N}$-acetylcysteine is another anti-oxidant drug that has effects on neurotransmission via its influence on cysteine and glutamate levels; and DAergic transmission. In trials, it had been associated with improvements in PANSS total and negative scales [283]; and improvement of PANSS positive and negative scales [284]. Also, as said earlier, minocycline's mechanism of action might involve the inhibition of formation of reactive oxygen species [239].

Abnormalities in polyunsaturated fatty acid (PUFA) metabolism have been implicated in the possible aetiopathogenesis of schizophrenia [285], A number of studies [286-289] have examined the possible effects of $\mathrm{N}-3$ PUFA eicosapentaenoic acid (EPA) when added as supplements to antipsychotics; with reports of positive improvement of primary efficacy and secondary outcomes $[288,289]$, there is also evidence suggesting that N-3 PUFA may reduce adverse effects secondary to antipsychotic use [286].

Hormones have been implicated in the possible aetiopathogenic mechanisms of schizophrenia; with reports of gender related-differences in schizophrenia [290] incidence, which have been largely attributed to the effects of gonadal steroids. The oestrogen hypothesis postulates that oestrogen exerts a neuroprotective effect in females, modulating the development and/or severity of schizophrenia [291]. In a number of studies, the beneficial effects of adjunctive treatment with oestrogen in males and/or females have been reported [292, 293]. The neuroprotective effect of oestrogen in schizophrenia has also been associated with its effect on the DA system [294]. In studies in which oestrogens were administered to post-menopausal women or women with chronic schizophrenia, there were reports of improvement in PANSS total, positive and negative scales [295] but in a few, no obvious benefit was demonstrated [296]. Also in studies examining the effect of the antioestrogen, raloxifene; improvement of PANSS total score [296], or PANSS positive and negative scales [297] were observed.

Melatonin has been linked to the aetiopathogenesis of schizophrenia [298]; and an emerging area in schizophrenia research focuses on the impact of immunomodulatory drugs like melatonin [119], with studies assessing the therapeutic potential of exogenous administration of melatonin. In a recent study using a ketamine model of schizophrenia in mice, significant improvements in behavioural and brain oxidative stress parameters were recorded following melatonin administration as a sole agent $[119,121]$ or adjunct [299]. The findings of the studies are in line with earlier observations that administration of melatonin may augment the efficacy of antipsychotics through suppression of neuroinflammation; and its potent antioxidative effects [300]. 
Other hormones such as oxytocin has been associated with improved performance in emotion recognition task [301], improvement of verbal memory [302]; and improvement of PANSS total, positive and negative scores [303]. Studies also showed improvement of cognitive function [304] and attention/memory functions [305] respectively, with erythropoietin. Pregnenolone [306] and dehydroepiandrosterone [307] have also been studied with favourable results.

Trace elements are important in antioxidant defence and regulation of metabolic reactions [308]. A number of studies have suggested that trace element deficiencies may be associated with the aetiology and pathophysiology of schizophrenia [309]. Zn is one of the trace elements whose abnormal homeostasis had been implicated in the expression of symptoms of schizophrenia [309]. Trial of $\mathrm{Zn}$ add-on therapy (to risperidone) has proven the efficacy of $\mathrm{Zn}$ as an adjuvant in the management of schizophrenia [310]. Also in an animal study, $\mathrm{Zn}$ proved beneficial (either as monotherapy or as adjunct to haloperidol or olanzapine) in the attenuation of behavioural deviations or brain antioxidant changes in mice that were given repeated ketamine injection [122]; although more research is needed to ascertain its role in schizophrenia management.

\section{Conclusions}

An evolving understanding of the aetiopathogenesis of schizophrenia has continued to improve our approach to the management of symptoms. However, while its aetiology is still not completely understood, and many factors had been implicated (and are still being implicated) in its evolution; our position regarding the understanding of the disorder is much stronger than it was centuries ago. Also, from decades of experience, it is obvious that appropriate application of drugs for the management of schizophrenia has its foundation in an adequate understanding of its aetiology; therefore, research must continue to be directed towards getting a complete picture of the causes of the disorder, as this is intimately-linked to the development, discovery and application of better therapeutic agents.

\section{Acknowledgements}

This research did not receive any specific grant from agencies in the public, commercial, or not-for-profit sectors.

\section{Conflict of Interest}

All authors of this paper declare that there is no conflict of interest related to the content of this manuscript.

\section{REFERENCES}

[1] Feigenson KA, Kusnecov AW, Silverstein SW (2014) Inflammation and the Two-Hit hypothesis of schizophrenia. Neurosci. Biobehav. Rev. 38: 72-93.

[2] Chan KY, Zhao FF, Meng S, Demaio AR, Reed C, et al (2015) Prevalence of schizophrenia in China between 1990 and 2010. J Glob Health 5:010410.

[3] Kahn RS, Sommer IE, Murray RM, Meyer-Lindenberg A, Weinberger DR, et al. (2015) Schizophrenia. Nat. Rev. Dis. Primers. 1:15067.

[4] Perkovic MN, Erjavec GN, Strac DS, Uzun S, Kozumplik O et al (2017) Theranostic biomarkers for schizophrenia. Int. J. Mol. Sci. 18: E733.

[5] Larson MK, Walker EF, Compton MT (2010) Early signs, diagnosis and therapeutics of the prodromal phase of schizophrenia and related psychotic disorders. Expert Rev. Neurother 10:1347-59.

[6] Halldorsdottir T, Binder EB (2017) Gene $\times$ Environment Interactions: From Molecular Mechanisms to Behavior. Annu. Rev. Psychol. 68:215-241.

[7] Nestler EJ, Hyman ES (2010) Animal Models of Neuropsychiatric Disorders. Nat Neurosci. 13: 1161-1169.

[8] Tsai J, Rosenheck RA (2013) Psychiatric co-morbidity among adults with schizophrenia: A latent class analysis. Psychiatry Res. 210:16-20.

[9] Kessler RC, Amminger GP, Aguilar-Gaxiola S, Alonso J, Lee S, Ustun BT (2007) Age of onset of mental disorders: a review of recent literature. Curr Opin Psychiatry. 20:359-364

[10] Laursen TM, Munk-Olsen T, Vestergaard M (2012) Life expectancy and cardiovascular mortality in persons with schizophrenia. Curr. Opin. Psychiatry. 25: 83-88.

[11] Becker A (2017) Chapter 16: Modeling schizophrenia: Focus on Developmental Models (ed.) Athineos Philippu (ed.), In Vivo Neuropharmacology and Neurophysiology, Neuromethods, vol. 121, Springer Science+Business Media New York.

[12] Giusti-Rodriguez P, Sullivan PF (2013) the genomics of schizophrenia: update and implications. J Clin Invest 123: 4557-4563.

[13] van Os J, Rutten BP, Poulton R (2008) Gene-environment interactions in schizophrenia: review of epidemiological findings and future directions. Schizophr Bull. 34: 1066-82.

[14] Rethelyi JM, Benkovits J, Bitter I (2013) Genes and environments in schizophrenia: the different pieces of a manifold puzzle. Neurosci Biobehav Rev 37: 2424-2437.

[15] Singh S, Kumar A, Agarwal S, Phadke SR, Jaiswal Y (2014) Genetic insight of schizophrenia: past and future perspectives. Gene. 535: 97-100.

[16] Dennison U, McKernan D, Cryan J, Dinan T (2012) 
Schizophrenia patients with a history of childhood trauma have a pro-inflammatory phenotype. Psychol Med. 42: 1865-71.

[17] Kyziridis TC (2005) Notes on the History of Schizophrenia. German J Psychiatry 8: 42-48.

[18] Burton N. (2012) A Brief History of Schizophrenia Psychology Today. Psychology Today: Retrieved June 7, 2017, from

http://www.psychologytoday.com/blog/hide-and-seek/2012 09/brief-history-schizophrenia

[19] Jablensky A (2010) the diagnostic concept of schizophrenia: its history, evolution, and future prospects Dialogues Clin Neurosci 12:271-287.

[20] Alexander FG, Selesnick ST (1966) the History of Psychiatry. An Evaluation of Psychiatric Thought and Practice from Prehistoric Times to the Present. New York, NY: Harper and Row.

[21] Geller JL (2000) the last half-century of psychiatric services as reflected in Psychiatric Services. In: Psychiatric Services. $51: 41-67$

[22] Kraepelin E (1971) Psychiatrie. 8 Auflage Leipzig, Austria: Barth; 1909. English translation and adaptation by Barclay RM, Robertson GM. Dementia Praecox and Paraphrenia. Huntington, NY: Krieger Publishing; 1919 Reprinted 1971.

[23] Andreasen NC (1997) the evolving concept of schizophrenia from Kraepelin to present and future. In: Schizophrenia Research. 28:105-9.

[24] Tartakovsky M (2012) History of Psychology: The Birth and Demise of Dementia Praecox. Psych Central. /psychcentral.com/blog/archives/2012/06/22/history-of-psy chology-the-birth-and-demise-of-dementia-praecox/ Retrieved on June 7, 2017.

[25] Bleuler (1911) Dementia Praecox: Or the Group of Schizophrenias. New York: International Universities Press.

[26] Bleuler E (1950) In: Dementia Praecox or the Group of Schizophrenias. Zinkin J, translator. New York, NY: International University Press.

[27] Pillmann F, Marneros A (2003) brief and acute psychoses: the development of concepts. Hist. Psychiatry 14:161-77.

[28] Kasanin J (1933) The acute schizoaffective psychosis. Am J Psychiatry. 90:97-126.

[29] Stephens JH, Astrup C (1963) Prognosis in "process" and "non-process" schizophrenia. Am J Psychiatry.119:945-953.

[30] Langfeld G (1956) The prognosis of schizophrenia. Acta Psychiatr Neurol Scand. 110:7-66.

[31] Tsuang MT, Winokur G (1974) Criteria for subtyping schizophrenia. Arch Gen Psychiatry. 31:43-47.

[32] Schneider K. (1959) 8th edition, 1950. Stuttgart, Germany: Thieme; 1950. English translation by Hamilton MW, Anderson EW. Clinical Psychopathology. New York, NY: Grune and Stratton; Klinische Psychopathologie.

[33] Waters FA, Badcock JC, Dragović M, Jablensky A (2009) Neuropsychological functioning in schizophrenia patients with first-rank (passivity) symptoms. Psychopathol. 42:47-58.

[34] Leonhard K (1999) 2nd ed. Classification of endogenous psychoses and their differentiated aetiology Vienna, Austria; New York, NY: Springer.

[35] Baron M, Risch N (1987) The spectrum concept of schizophrenia: evidence for a genetic-environmental continuum J Psychiatr Res. 21:257-67.

[36] Rado S (1960) Theory and therapy: the theory of schizotypal organization and its application to the treatment of decompensated schizotypal behaviour. In: Scher SC, Davis HR, eds. The Outpatient Treatment of Schizophrenia New York, NY: Grune and Stratton.

[37] Meehl PE. (1973) Schizotaxia, schizotypy, schizophrenia/ in Meehl PE, Psychodiagnosis: Selected Papers. Pg 135-155, Minneapolis, MN: University of Minnesota Press.

[38] Chapman LJ, Chapman JP (1980) Scales for rating psychotic and psychotic-like experiences as continua. Schizophr Bull. 6:477-89.

[39] World Health Organization (1992) The ICD-10 Classification of Mental and Behavioural Disorders: Clinical Descriptions and Diagnostic Guidelines.

[40] American Psychiatric Association (2013) Diagnostic and Statistical Manual of Mental Disorders (5th ed.). Arlington: American Psychiatric Publishing. 101-05.

[41] Liddle PF (1987) The symptoms of chronic schizophrenia. A re-examination of the positive-negative dichotomy. $\mathrm{Br} \mathrm{J}$ Psychiatry 151: 145-151.

[42] Carpenter WT Jr, Heinrichs DW, Wagman AM (1988) Deficit and non deficit forms of schizophrenia: the concept. Am J Psychiatry. 145:578-83.

[43] Kirkpatrick B, Buchanan RW, Breier A, Carpenter WT Jr (1993) Case identification and stability of the deficit syndrome of schizophrenia Psychiatry Res. 47:47-56.

[44] Kirkpatrick B, Buchanan RW, Ross DE, Carpenter WT Jr (2001) A separate disease within the syndrome of schizophrenia. Arch Gen Psychiatry. 58:165-71.

[45] Cuesta MJ, Peralta V (2001) Integrating psychopathological dimensions in functional psychoses: a hierarchical approach Schizophr Res. 52:215-29.

[46] McGrath JA, Nestadt G, Liang KY, Lasseter VK, Wolyniec PS et al (2004) Five latent factors underlying schizophrenia: analysis and relationship to illnesses in relatives. Schizophr Bull. 30:855-73.

[47] Lyons MJ, Kremen WS, Tsuang MT. Faraone SV (1989) Investigating putative genetic and environmental forms of schizophrenia: methods and findings. Int Rev Psychiatr. $1: 259-276$

[48] Roy MA, Crowe RR (1994) Validity of the familial and sporadic subtypes of schizophrenia. Am J Psychiatry.151:805-14.

[49] Braff DL, Ryan J, Rissling AJ, Carpenter WT (2013) Lack of use in the literature from the last 20 years supports dropping traditional schizophrenia subtypes from DSM-5 and ICD-11. 
Schizophr Bull. 39:751-3.

[50] Carr VJ, Neil AL, Halpin SA, Holmes S, Lewin TJ (2003) Costs of schizophrenia and other psychoses in urban Australia: findings from the Low Prevalence (Psychotic) Disorders Study. Aust N Z J Psychiatry. 37:31-40.

[51] Wu EQ, Birnbaum HG, Shi L, Ball DE, Kessler RC et al (2005) The economic burden of schizophrenia in the United States in 2002. J Clin Psychiatry 66: 1122-29.

[52] McGrath J, Saha S, Chant D, Welham J (2008) Schizophrenia: a concise overview of incidence, prevalence, and mortality. Epidemiol Rev. 30:67-76.

[53] Lieberman JA (1999) Is schizophrenia a neurodegenerative disorder? A clinical and neurobiological perspective. Biol. Psychiatry 46:729-39.

[54] Meyer U, Schwarz MJ, Müller N (2011) schizophrenia: a promising neuro-immunological target for the treatment of negative/cognitive symptoms and beyond. Pharmacol Ther. 132:96-110.

[55] Kirch DG (1993) Infection and autoimmunity as etiologic factors in schizophrenia: a review and reappraisal. Schizophr. Bull. 19:355-70.

[56] Ganguli R, Brar JS, Rabin BS (1994) Immune abnormalities in schizophrenia: evidence for the autoimmune hypothesis. Harv. Rev. Psychiatry. 2:70-83.

[57] Manji H, Gottesman II, Gould T: (2004) Signal transduction and genes-to-behaviors pathways in psychiatric diseases. Sci. STKE. 207: Pe49.

[58] Petronis A (2004) The origin of schizophrenia: Genetic thesis, epigenetic antithesis, and resolving synthesis. Biol. Psychiatry. 55:142-146. 10.

[59] Brown AS (2011) The environment and susceptibility to schizophrenia. Prog Neurobiol. 93(1): 23-58.

[60] Magalhães PV, Dean O, Andreazza AC, Berk M, Kapczinski F (2016) Antioxidant treatments for schizophrenia. Cochrane Database Syst Rev 5; 2: CD008919.

[61] Hanson DR, Gottesman II (2005) Theories of schizophrenia: a genetic-inflammatory-vascular synthesis BMC Medical Genetics. 6:7.

[62] Insel TR (2010) Rethinking schizophrenia. Nature 11; 468: 187-93.

[63] Gratten J, Wray NR, Keller MC, Visscher PM (2014) Large-scale genomics unveils the genetic architecture of psychiatric disorders. Nat Neurosci. 17:782-90.

[64] Harrison PJ (2015) Recent genetic findings in schizophrenia and their therapeutic relevance. J Psychopharmacol 29:85-96.

[65] O'Connell G, Lawrie SM, McIntosh AM, Hall J (2011) Schizophrenia risk genes: Implications for future drug development and discovery. Biochem Pharmacol. 81:1367-73.

[66] Muglia P (2011) from genes to therapeutic targets for psychiatric disorders - what to expect? Curr Opin Pharmacol. 11:563-71.
[67] McCarroll SA, Hyman SE (2013) Progress in the genetics of polygenic brain disorders: significant new challenges for neurobiology. Neuron. 80:578-87.

[68] Law AJ, Shannon Weickert C, Hyde TM, Kleinman JE, Harrison PJ (2004) Neuregulin-1 (NRG-1) mRNA and protein in the adult human brain. Neurosci. 127:125-36.

[69] Li D, Collier DA, He L (2006) Meta-analysis shows strong positive association of the neuregulin 1 (NRG1) gene with schizophrenia. Hum Mol Genet. 15:1995-2002.

[70] Fisahn A, Neddens J, Yan L, Buonanno A (2009) Neuregulin-1 modulates hippocampal gamma oscillations: Implications for schizophrenia. Cereb Cortex 19:612-618.

[71] Millar JK, Wilson-Annan JC, Anderson S, Christie S, Taylor MS et al ( 2000) Disruption of two novel genes by a translocation co-segregating with schizophrenia. Hum Mil Genet 22:1415-23.

[72] Kivimae S, Martin PM, Ruan Y, Heberlein U, Rubenstein JLR et al (2011) Abnormal behavior in mice mutant for the Disc1 binding partner, Dixdc1. Transl. Psychiatry 1:1-5.

[73] Guo AY, Sun J, Riley BP, Thiselton DL, Kendler KS, et al. (2009) The dystrobrevin-binding protein 1 gene: features and networks. Mol Psychiatry. 14:18-29.

[74] Abdolmaleky HM Pajouhanfar S, Faghankhani M, Joghataei MT, Mostafavi A, Thiagalingam S et al (2015) Antipsychotic drugs attenuate aberrant DNA methylation of DTNBP1 (dysbindin) promoter in saliva and post-mortem brain of patients with schizophrenia and Psychotic bipolar disorder. Am J Med Genet B Neuropsychiatr Genet. 168:687-96

[75] Bakanidze G, Brandl EJ, Hutzler C, Aurass F, Onken S et al (2016) Association of Dystrobrevin-Binding Protein 1 Polymorphisms with Sustained Attention and Set-Shifting in Schizophrenia Patients. Neuropsychobiol. 74:41-47.

[76] Sacchetti P, Carpentier R, Ségard P, Olivé-Cren C, Lefebvre $P$ (2006) Multiple signaling pathways regulate the transcriptional activity of the orphan nuclear receptor NURR1. Nucleic Acids Res. 34:5515-27.

[77] Craddock N, O'Donovan MC, Owen MJ (2005) The genetics of schizophrenia and bipolar disorder: dissecting psychosis. J Med Genet. 42:193-204.

[78] Niwa M, Kamiya A, Murai R, Kubo K, Gruber AJ et al (2010) Knockdown of DISC1 by in utero gene transfer disturbs postnatal dopaminergic maturation in the frontal cortex and leads to adult behavioral deficits Neuron. $65: 480-9$.

[79] Cardno A, Gottesman II (2000) Twin studies of schizophrenia: from bow-and-arrow concordance to Star Wars Mx and functional genomics. Am J Med Genet. 97:12-17.

[80] Jiang Z, Rompala GR, Zhang S, Cowell RM, Nakazawa K (2012) Social isolation exacerbates schizophrenia-like phenotypes via oxidative stress in cortical interneurons. Biol Psychiatry. 73:1024-34.

[81] Marcelis M, Takei N, van Os J (1999) Urbanization and risk for schizophrenia: does the effect operate before or around the time of illness onset? Psychol Med. 29:1197-203. 
[82] March D, Hatch SL, Morgan C, Kirkbride JB, Bresnahan M et al (2008) Psychosis and place. Epidemiol. Rev. $30: 84-100$

[83] Mortensen PB, Pedersen CB, Westergaard T, Wohlfahrt J, Ewald H et al (1999) Effects of family history and place and season of birth on the risk of schizophrenia. N Engl J Med. $340: 603-8$

[84] McGrath J, Scott J (2006) Urban birth and risk of schizophrenia: a worrying example of epidemiology where the data are stronger than the hypotheses Epidemiol Psichiatr Soc. 15:243-6.

[85] Cantor-Graae E, Selten JP (2005) Schizophrenia and migration: a meta-analysis and review. Am J Psychiatry. $162: 12-24$

[86] Veling W, Susser E (2011) Migration and psychotic disorders. Expert Rev Neurother. 11:65-76.

[87] Babulas V, Factor-Litvak P, Goetz R, Schaefer CA, Brown AS (2006) Prenatal exposure to maternal genital and reproductive infections and adult schizophrenia. Am J Psychiatry. 163:927-9.

[88] Opler M, Charap J, Greig A, Stein V, Polito S, Malaspina D (2013) Environmental Risk Factors and Schizophrenia, Int. J. Mental Health. 42:23-32.

[89] Brown A, Patterson P (2011) Maternal infection and schizophrenia: Implications for prevention. Schizophrenia Bull. 37:284-290.

[90] Sørensen HJ, Mortensen EL, Reinisch JM, Mednick SA (2009) Association between prenatal exposure to bacterial infection and risk of schizophrenia. Schizophr Bull. $35: 631-7$.

[91] Clarke MC, Tanskanen A, Huttunen M, Whittaker JC, Cannon M (2009) Evidence for an interaction between familial liability and prenatal exposure to infection in the causation of schizophrenia. Am J Psychiatry. 166:1025-30

[92] Cieslak K, Feingold J, Antonius D, Walsh-Messinger J, Dracxler R et al (2014) Low vitamin D levels predict clinical features of schizophrenia. Schizophr Res 159:543-545.

[93] Graham KA, Keefe RS, Lieberman JA, Calikoglu AS, Lansing KM et al (2014) Relationship of low vitamin D status with positive, negative and cognitive symptom domains in people with first-episode schizophrenia. Early Interv Psychiatry 9:397

[94] McGrath JJ, Burne TH, Feron F (2010) Developmental vitamin D deficiency and risk of schizophrenia: a 10-year update. Schizophr Bull. 36:1073-107.

[95] Eyles DW, Burne TH, McGrath JJ (2013) Vitamin D, effects on brain development, adult brain function and the links between low levels of vitamin D and neuropsychiatric disease. Front Neuroendocrinol. 34:47-64.

[96] Brown AS, Susser ES (2008) Prenatal nutritional deficiency and risk of adult schizophrenia. Schizophrenia Bull. 34:1054-1063.

[97] Spauwen J, Krabbendam L, Lieb R, Wittchen HU, van Os J (2004) Early maternal stress and health behaviours and offspring expression of psychosis in adolescence. Acta
Psychiatrica Scandinavica. 110:356-364.

[98] Arseneault L, Cannon M, Poulton R, Murray R, Caspi A et al (2002) Cannabis use in adolescence and risk for adult psychosis: longitudinal prospective study. BMJ. 325:1212-3.

[99] Corcoran C, Perrin M, Harlap S, Deutsch L, Fennig S et al (2009) Effect of socioeconomic status and parents' education at birth on risk of schizophrenia in offspring. Soc Psychiatry Psychiatr Epidemiol. 44:265-71.

[100] Morgan C, Fisher H (2007) Environment and schizophrenia: environmental factors in schizophrenia: childhood trauma--a critical review. Schizophr Bull. 33:3-10.

[101] O'Donnell K, O'Connor TG, Glover V (2009). Prenatal stress and neurodevelopment of the child: Focus on the HPA axis and role of the placenta. Developmental Neurosci. 31:285-292.

[102] Becker A, Eyles DW, McGrath JJ, Grecksch G (2005) Transient prenatal vitamin D deficiency is associated with subtle alterations in learning and memory functions in adult rats. Behav Brain Res 161:306.

[103] Meyer U, Feldon J (2010) Epidemiology-driven neurodevelopmental animal models of schizophrenia. Prog. Neurobiol. 90:285-326.

[104] Burns JK (2004) An evolutionary theory of schizophrenia: cortical connectivity, metarepresentation, and the social brain. Behav Brain Sci. 2:831-55.

[105] Goodman AB, Pardee AB (2000) Meeting report; "Molecular neurobiological mechanisms in schizophrenia: seeking a synthesis". Biol Psychiatry. 48:173-83.

[106] Dean B (2002) Understanding the pathology of schizophrenia: recent advances from the study of the molecular architecture of postmortem CNS tissue Postgrad Med J. 78:142-148.

[107] Thompson PM, Egbufoama S, Vawter MP (2003) SNAP-25 reduction in the hippocampus of patients with schizophrenia. Prog. Neuropsychopharmacol. Biol. Psychiatry. 27: 411-417.

[108] Turner KM, Burgoyne RD, Morgan A (1999) Protein phosphorylation and the regulation of synaptic membrane traffic. Trends Neurosci. 22:459-64.

[109] Lewis CM, Levinson DF, Wise LH, De Lisi LE, Straub RE et al. (2003) Genome scan meta-analysis of schizophrenia and bipolar disorder, part II: Schizophrenia. Am. J. Hum. Genet. 73:34-48.

[110] Matosin N, Fernandez-Enright F, Lum JS, Engel M, Andrews JL et al (2016) Molecular evidence of synaptic pathology in the CA1 region in schizophrenia. NPJ Schizophr. 2:16022

[111] Howes OD, Kapur S (2009) The Dopamine Hypothesis of Schizophrenia: Version III-The Final Common Pathway. Schizophr Bull. 35: 549-562.

[112] Moghaddam B, Krystal JH (2012) Capturing the angel in "angel dust": twenty years of translational neuroscience studies of NMDA receptor antagonists in animals and humans. Schizophr Bull. 38: 942-9.

[113] Becker A, Grecksch G, Bernstein HG Höllt V, Bogerts B 
(1999) Social behaviour in rats lesioned with ibotenic acid in the hippocampus: quantitative and qualitative analysis. Psychopharmacol. (Berl). 144:333-338.

[114] Becker A, Grecksch G (2000) Social memory is impaired in neonatally ibotenic acid lesioned rats. Behav Brain Res. 109:137-140.

[115] Grecksch G, Bernstein HG, Becker A Höllt V, Bogerts B (1999) Disruption of latent inhibition in rats with postnatal hippocampal lesions. Neuropsychopharmacol. 20:525-532.

[116] Swerdlow NR, Light GA, Breier MR Shoemaker JM, Saint Marie RL et al (2012) Sensory and sensorimotor gating deficits after neonatal ventral hippocampal lesions in rats. Dev Neurosci. 34:240-249.

[117] Vazquez-Roque RA, Ramos B, Tecuatl C Juárez I, Adame A et al (2012) Chronic administration of the neurotrophic agent cerebrolysin ameliorates the behavioral and morphological changes induced by neonatal ventral hippocampus lesion in a rat model of schizophrenia. J Neurosci Res. 90:288-306.

[118] Jaramillo-Loranca BE， Garces-Ramirez L, Munguia Rosales AA, Luna Ramírez C, Vargas Hernández G et al (2015) The sigma agonist 1,3-di-o-tolyl-guanidine reduces the morphological and behavioral changes induced by neonatal ventral hippocampus lesion in rats. Synapse. 69:213-225.

[119] da Silva Araújo T, Maia Chaves Filho AJ, Monte AS, Isabelle de Góis Queiroz A, Cordeiro RCet al (2017) Reversal of schizophrenia-like symptoms and immune alterations in mice by immunomodulatory drugs. J Psychiatr Res. 84:49-58.

[120] Onaolapo OJ, Paul TB, Onaolapo AY (2017b). Comparative effects of sertraline, haloperidol or olanzapine treatments on ketamine-induced changes in mouse behaviours. Metab Brain Disease. in press. doi: 10.1007/s11011-017-0031-3.

[121] Onaolapo AY, Aina OA, Onaolapo OJ (2017b) Melatonin attenuates behavioural deficits and reduces brain oxidative stress in a rodent model of schizophrenia Biomed. Pharmacother. 92, 373-383.

[122] Onaolapo OJ, Ademakinwa OQ, Olalekan TO, Onaolapo AY (2017c) Ketamine-induced behavioural and brain oxidative changes in mice: an assessment of possible beneficial effects of Zinc as mono- or adjunct therapy. Psychopharmacol. (Berl). in press, doi: 10.1007/s00213-017-4666-x.

[123] Parikh V, Kutlu MG, Gould TJ (2016) nAChR dysfunction as a common substrate for schizophrenia and comorbid nicotine addiction: current trends and perspectives Schizophr Res. 171(0): 1-15.

[124] Raedler TJ, Bymaster FP, Tandon R, Copolov D, Dean B. (2007) Towards a muscarinic hypothesis of schizophrenia. Mol Psychiatry. 12:232-46.

[125] Holt DJ, Bachus SE, Hyde TM, Wittie M, Herman MM et al. (2005) Reduced density of cholinergic interneurons in the ventral striatum in schizophrenia: an in situ hybridization study. Biol Psychiatry. 58:408-416.

[126] Bennett Jr JP, Enna SJ, Bylund DB, Gillin JC, Wyatt RJ, et al (1979) Neurotransmitter receptors in frontal cortex of schizophrenics. Arch Gen Psychiatry. 36:927-934.

[127] Tandon R, De Quardo JR, Goodson J, Mann NA, Greden JF (1992) Effect of anticholinergics on positive and negative symptoms in schizophrenia. Psychopharmacol Bull. 2:297-302.

[128] Dewey SL, Smith GS, Logan J, Brodie JD, Simkowitz P et al (1993) Effects of central cholinergic blockade on striatal dopamine release measured with positron emission tomography in normal human subjects. Proc Natl Acad Sci USA. 90:11816-20

[129] Howes OD, Kambeitz J, Kim E, Stahl D, Slifstein M et al. (2012) The nature of dopamine dysfunction in schizophrenia and what this means for treatment. Arch Gen Psychiatry 69:776-86.

[130] Seeman P, Lee T (1975) Antipsychotic drugs: direct correlation between clinical potency and presynaptic action on dopamine neurons. Science. 188:1217-1219.

[131] Snyder SH (1976) The dopamine hypothesis of schizophrenia: focus on the dopamine receptor. Am J Psychiatry. 133:197-202.

[132] Howes O, Bose S, Turkheimer F, Valli I, Egerton A, et al. (2011) Progressive increase in striatal dopamine synthesis capacity as patients develop psychosis: a PET study. Mol Psychiatry. 16:885-6.

[133] Carlsson A, Lindqvist M (1963) Effect of chlorpromazine or haloperidol on formation of 3methoxytyramine and normetanephrine in mouse brain. Acta Pharmacol Toxicol. (Copenh). 20:140-4

[134] Carlsson A, Lindqvist M, Magnusson T (1957) 3, 4-Dihydroxyphenylalanine and 5 hydroxytryptophan as reserpine antagonists Nature. 180:1200.

[135] Seeman P, Lee T, Chau-Wong M, Wong K (1976) Antipsychotic drug doses and neuroleptic/dopamine receptors Nature. 261:717-9.

[136] Keshavan MS, Tandon R, Boutrous NN, Nasrallah HA (2008) Schizophrenia, "just the facts": what we know in 2008 part 3: neurobiology. Schizophrenia Res. 106:89-107.

[137] Davis KL, Kahn RS, Ko G, Davidson M (1991) Dopamine in schizophrenia: a review and reconceptualization. Am J Psychiatry. 148:1474-86.

[138] Abi-Dargham A, Laruelle M (2005) Mechanism of action of second generation antipsychotic drugs in schizophrenia: insights from brain imaging studies. Eur. Psychiatry. $20: 15-27$.

[139] Lindström LH, Gefvert O, Hagberg G, Lundberg T, Bergström M, et al (1999) Increased dopamine synthesis rate in medial prefrontal cortex and striatum in schizophrenia indicated by L-(beta-11C) DOPA and PET. Biol Psychiatry. 46:681-8.

[140] Laruelle M, Iyer RN, al-Tikriti MS, Zea-Ponce Y, Malison $\mathrm{R}$ et al (1997) Microdialysis and SPECT measurements of amphetamine-induced dopamine release in nonhuman primate. Synapse. 25:1-14.

[141] Abi-Dargham A, Rodenhiser J, Printz D, Zea-Ponce Y, Gil 
$R$ et al (2000) Increased baseline occupancy of D2 receptors by dopamine in schizophrenia. Proc Natl Acad Sci U S A. 97:8104-9.

[142] Zakzanis KK, Hansen KT (1998) Dopamine D2 densities and the schizophrenic brain. Schizophr Res. 32:201-6.

[143] Guo N, Hwang DR, Lo ES, Huang YY, Laruelle M et al (2003) A Dopamine depletion and in vivo binding of PET D1 receptor radioligands: implications for imaging studies in schizophrenia. Neuropsychopharmacol. 28:1703-11

[144] Tamminga CA (2006). The neurobiology of cognition in schizophrenia J Clin Psychiatry. 67:e11.

[145] Shi J, Gershon ES, Liu C (2008) Genetic associations with schizophrenia: meta-analyses of 12 candidate genes. Schizophr Res. 104:96-107.

[146] Boksa P (2004) Animal models of obstetric complications in relation to schizophrenia Brain Res Brain Res Rev. 45:1-17.

[147] Kahn RS, Sommer IE (2015) The neurobiology and treatment of first-episode schizophrenia. Mol Psychiatry 20:84-97.

[148] Wooley DW, Shaw E (1954) A biochemical and pharmacological suggestion about certain mental disorders. Proc Natl Acad Sci USA. 40:228-231.

[149] Gaddum JH, Hameed KA (1954) Drugs which antagonize 5-hydroxytryptamine. Br J Pharmacol. 9:240-248.

[150] Woolley DW (1962). The biochemical basis of psychosis. The serotonin hypothesis about mental diseases. New York: J. Wiley \& Sons Inc.

[151] Glennon RA. (1990) Do classical hallucinogens act as 5-HT2 agonists or antagonistss? Neuropsychopharmacol. 3:509-517.

[152] Abraham HD, Aldridge AM., Gorgia P (1996). The psychopharmacology of hallucinogens. Neuropsychopharmacol. 14:285-298.

[153] Gouzoulis-Mayfrank, E, Habermeyer E, Hermle L, Steinmeyer A, Kunert H, et al (1998) Hallucinogenic drug induced states resemble acute endogenous psychoses: results of an empirical study. Eur. Psychiatry. 13:399-406.

[154] Waters F, Collerton D, Ffytche DH, Jardri R, Pins D, et al (2014) Visual hallucinations in the psychosis spectrum and comparative information from neurodegenerative disorders and eye disease. Schizophr Bull. 40:S233-45.

[155] Geyer MA, Vollenweider FX (2008) Serotonin research: contributions to understanding psychoses. Trends Pharmacol Sci. 29:445-53

[156] González-Maeso J, Weisstaub NV, Zhou M, Chan P, Ivic L et al (2007) Hallucinogens recruit specific cortical 5-ht2a receptor-mediated signalling pathways to affect behavior. Neuron. 53:439-452.

[157] Roth B, Meltzer HY (2000) The Role of Serotonin in Schizophrenia (eds.) Bloom FE, Kupfer DJ, in Psychopharmacology: The Fourth Generation of Progress, Lippincott Williams \& Wilkins, 4th edition.
[158] Meltzer HY, Matsubara S, Lee J-C (1989) Classification of typical and atypical antipsychotic drugs on the basis of dopamine D-1, D-2 and serotonin 2 pKi values. J Pharmacol Exp Ther. 251:238-246.

[159] Braff, DL, Geyer MA, Swerdlow NR (2001) Human studies of prepulse inhibition of startle: normal subjects, patient groups, and pharmacological studies. Psychopharmacol. (Berl.) 156:234-258

[160] Ludewig K Geyer MA, Vollenweider FX. (2003) Deficits in prepulse inhibition and habituation in never-medicated first-episode schizophrenia. Biol. Psychiatry. 54:121-128

[161] Vollenweider FX Csomor PA, Knappe B, Geyer MA, Quednow BB. (2007). The effects of the preferential 5-HT2A agonist psilocybin on prepulse inhibition of startle in healthy human volunteers depend on interstimulus interval. Neuropsychopharmacol. 32:1876-1887

[162] Abi-Dargham, Laruell M, Aghajanian GK, Charney D, Krystal J (1997). The role of serotonin in the pathophysiology and treatment of schizophrenia. Neuropsychiatr Clin Neurosci. 9:1-17.

[163] Carter OL, Hasler F, Pettigrew JD, Wallis GM, Liu GB et al (2007) Psilocybin links binocular rivalry switch rate to attention and subjective arousal levels in humans. Psychopharmacol. (Berl.) 195:415-424.

[164] Vollenweider FX, Geyer MA (2001) A systems model of altered consciousness: integrating natural and drug-induced psychoses. Brain Res. Bull. 56:495-507.

[165] Hurlemann, R Matusch A, Kuhn KU, Berning J, Elmenhorst D et al. (2008) 5-HT2A receptor density is decreased in the at-risk mental state. Psychopharmacol. (Berl.) 195:579-590.

[166] Meltzer HY, Fatemi SH (1996). The role of serotonin in schizophrenia and the mechanism of action of antipsychotic drugs. Serotonergic mechanisms. In: Antipsychotic treatment. Kane JM, Moller H-J, Awouters F, eds. 77-107, Marcel Dekker, New York.

[167] Maes M, Meltzer HY (1996) Effects of meta-chlorophenylpiperazine on neuroendocrine and behavioral responses in male schizophrenic patients and normal volunteers. Psychiatry Res. 64:147-169

[168] Dean B (2000) Signal transmission, rather than reception, is the underlying neurochemical abnormality in schizophrenia. Aust N Z J Psychiatry. 34:560-9.

[169] Riley BP, McGuffin P (2000) Linkage and associated studies of schizophrenia. Am J Med Genet. 97:23-44.

[170] Kouzmenko AP, Scaffidi A, Pereira AM, Hayes WL, Copolov DL et al (1999) No correlation between A(-1438)G polymorphism in 5-HT2A receptor gene promoter and the density of frontal cortical 5-HT2A receptors in schizophrenia. Hum Hered. 49:103-5.

[171] Kouzmenko AP, Hayes WL, Pereira AM, Dean B, Burnet PW et al (1997) 5-HT2A receptor polymorphism and steady state receptor expression in schizophrenia. Lancet. 349:1815.

[172] Olney JW, Farber NB (1995) Glutamate receptor dysfunction and schizophrenia. Arch Gen Psychiatry. 52:998-1007. 
[173] Krystal JH, Karper LP, Seibyl JP, Freeman GK, Delaney R et al. (1994) Subanesthetic effects of the noncompetitive NMDA antagonist, ketamine, in humans. Psychotomimetic, perceptual, cognitive, and neuroendocrine responses. Arch Gen Psychiatry. 51:199-214.

[174] Javitt DC (2007) Glutamate and Schizophrenia: Phencyclidine, N-Methyl-d-Aspartate Receptors, and Dopamine-Glutamate Interactions. Int Rev Neurobiol. 78:69-108.

[175] Stone JM, Davis JM, Leucht S, Pilowsky LS (2009) Cortical dopamine D2/D3 receptors are a common site of action for antipsychotic drugs--an original patient data meta-analysis of the SPECT and PET in vivo receptor imaging literature. Schizophr Bull. 35:789.

[176] Moghaddam B, Adams B, Verma A, Daly D (1997) Activation of glutamatergic neurotransmission by ketamine: a novel step in the pathway from NMDA receptor blockade to dopaminergic and cognitive disruptions associated with the prefrontal cortex. J. Neurosci. 17:2921-2927.

[177] Kim S, Lee H, Kim HJ, Bang E, Lee SH et al (2011) In vivo and ex vivo evidence for ketamine-induced hyperglutamatergic activity in the cerebral cortex of the rat: Potential relevance to schizophrenia. NMR Biomed. 24:1235-42.

[178] Bubenıkova-Valesova V, Horacek J, Vrajova M, Hoschl C (2008) Models of schizophrenia in humans and animals based on inhibition of NMDA receptors. Neurosc Biobehav Rev. 32:1014-23.

[179] Dawson N, Morris BJ, Pratt JA (2013) Subanesthetic Ketamine Treatment Alters Prefrontal Cortex Connectivity With Thalamus and Ascending Subcortical Systems. Schizophr. Bull.. 39:366-377.

[180] Egerton A, Reid L, McGregor S, Cochran SM, Morris BJ et al. (2008) Subchronic and chronic PCP treatment produces temporally distinct deficits in attentional set shifting and prepulse inhibition in rats. Psychopharmacol. (Berl) 198:37-49.

[181] Featherstone RE, Liang Y, Saunders Ja, Tatard-Leitman VM, Ehrlichman RS et al (2012) Subchronic ketamine treatment leads to permanent changes in EEG cognition and the astrocytic glutamate transporter EAAT2 in mice. Neurobiol Dis. 47:338-46.

[182] Maynard TM, Sikich L, Lieberman JA, LaMantia AS (2001) Neural development, cell-cell signaling, and the "two-hit" hypothesis of schizophrenia. Schizophr Bull. 27:457-76.

[183] Rapoport JL, Addington AM, Frangou S, Psych MR (2005) The neurodevelopmental model of schizophrenia: update 2005. Mol Psychiatry. 10:434-49.

[184] Fatemi SH, Folsom TD (2009) The Neurodevelopmental Hypothesis of Schizophrenia, Revisited. Schizophr Bull. 35: 528-548.

[185] Keshavan MS (1999) Development, disease and degeneration in schizophrenia: a unitary pathophysiological model. J Psychiatr Res. 33:513-21.

[186] Keshavan MS, Hogarty GE (1999) Brain maturational processes and delayed onset in schizophrenia. Dev Psychopathol. 11:525-43.
[187] Davis J, Eyre H, Jacka FN, Dodd S, Dean O (2016) A review of vulnerability and risks for schizophrenia: Beyond the two hit hypothesis. Neurosci Biobehav Rev. 65:185-94.

[188] Bilbo SD, Schwarz JM (2012). The immune system and developmental programming of brain and behavior. Front Neuroendocrinol. 33:267-86.

[189] Fan X, Goff DC, Henderson DC (2007) Inflammation and schizophrenia Expert Rev Neurother. 7:789-96.

[190] Brown AS, Derkits EJ (2010). Prenatal infection and schizophrenia: a review of epidemiologic and translational studies. Am J Psychiatry. 167:261-80.

[191] Costa E, Dong E, Grayson DR, Guidotti A, Ruzicka W et al (2007) Reviewing the role of DNA (cytosine-5) methyltransferase overexpression in the cortical GABAergic dysfunction associated with psychosis vulnerability. Epigenetics. 2: 29-36.

[192] Fineberg AM, Ellman LM (2013) Inflammatory cytokines and neurological and neurocognitive alterations in the course of schizophrenia. Biol Psychiatry. 73:951-66.

[193] Doorduin J, de Vries EF, Willemsen AT, de Groot JC, Dierckx RA et al (2009) Neuroinflammation in schizophrenia-related psychosis: a PET study. J Nucl Med. 50:1801-7.

[194] Schwarcz R, Rassoulpour A, Wu HQ, Medoff D, Tamminga CA., Roberts RC (2001) Increased cortical kynurenate content in schizophrenia. Biol. Psychiatry. 50: 521-530.

[195] Jones KA, Thomsen C (2013). The role of the innate immune system in psychiatric disorders. Mol Cell Neurosci. 53:52-62.

[196] Arnedo J, Svrakic DM, Del Val C, Romero-Zaliz R Hernandez-Cuervo $\mathrm{H}$ et al (2014) Uncovering the hidden risk architecture of the schizophrenias: confirmation in three independent genome-wide association studies. Am. J Psychiatry. 172:139-153.

[197] Kranz TM, Berns A, Shields J, Rothman K, Walsh-Messinger J et al (2016). Phenotypically distinct subtypes of psychosis accompany novel or rare variants in four different signalling genes. E-BioMed. 6:206-214.

[198] Wimberley T, Støvring H, Sørensen HJ, Horsdal HT, MacCabe JH, Gasse C (2016) Predictors of treatment resistance in patients with schizophrenia: a population-based cohort study. Lancet Psychiatry. 3:358-366.

[199] Howes OD, Kapur S (2014) A neurobiological hypothesis for the classification of schizophrenia: type A (hyperdopaminergic) and type B (normodopaminergic). Br. J. Psychiatry. 205:1-3.

[200] Maric NP, Jovicic MJ, Mihaljevic M, Miljevic C (2016) Improving Current Treatments for Schizophrenia. Drug Dev. Res. 77:357-367.

[201] Delay J, Deniker P, Harl Grasset A (1952) [N-dimethylaminoprophylchlorophenothiazine (4560 RP) therapy of confusional states]. Ann Med Psychol. (Paris) 110:398-403.

[202] Ramachandraiah CT, Subramaniam N, Tancer M (2009). The story of antipsychotics: Past and present. Indian $\mathbf{J}$ 
Psychiatry. 51:324-326.

[203] López-Muñoz F, Alamo C, Cuenca E, Shen WW, Clervoy P et al (2005) History of the discovery and clinical introduction of chlorpromazine. Ann Clin Psychiatry. $17: 113-35$

[204] Seeman P (2002) Atypical antipsychotics: mechanism of action. Can. J Psychiatry. 47:27-38.

[205] Kapur S, Zipursky R, Jones C, Shammi CS, Remington G et al (2000) A positron emission tomography study of quetiapine in schizophrenia: a preliminary finding of an antipsychotic effect with only transiently high dopamine D2 receptor occupancy. Arch. Gen. Psychiatry/ 57:553-559.

[206] Miyamoto S, Duncan GE, Marx CE, Lieberman JA (2005) Treatments for schizophrenia: a critical review of pharmacology and mechanisms of action of antipsychotic drugs. Mol. Psychiatry. 10:79-104.

[207] Kane, G. Honigfeld, J. Singer, and H. Meltzer (1988) Clozapine for the treatment-resistant schizophrenic. A double-blind comparison with chlorpromazine. Arch. Gen. Psychiatry. 45:789-796.

[208] Sadock BJ. (2009) Kaplan and Sadock's Comprehensive Textbook of Psychiatry. 9th ed. Lippincott Williams \& Wilkins, Philadelphia, USA.

[209] Mortimer A, Singh P, Shepherd C, Puthiryackal J (2010) Clozapine for Treatment-Resistant Schizophrenia: National Institute of Clinical Excellence (NICE) Guidance in the Real World. Clin Schizophr Relat Psychoses. 4:49-55.

[210] Remington G, Kapur S, Foussias G, Agid O, Mann S et al (2012) Tetrabenazine augmentation in treatment-resistant schizophrenia: a 12-week, double-blind, placebo-controlled trial. J Clin Psychopharmacol. 32:95-9.

[211] Demjaha A, Murray RM, McGuire PK et al. (2012) Dopamine synthesis capacity in patients with treatment-resistant schizophrenia. Am J Psychiatry. 169:1203-10.

[212] Murphy BP, Chung Y-C, Park T-W, McGorry PD (2006) Pharmacological treatment of primary negative symptoms in schizophrenia: a systematic review. Schizophr Res. 88:5-25.

[213] Kim E, Howes OD, Turkheimer FE, Kim BH, Jeong JM et al. (2013) The relationship between antipsychotic D2 occupancy and change in frontal metabolism and working memory: A dual [(11)C] raclopride and [(18) F] FDG imaging study with aripiprazole. Psychopharmacol (Berl). 227:221-9.

[214] Bressan RA, Erlandsson K, Jones HM et al (2003) Is regionally selective D2/D3 dopamine occupancy sufficient for atypical antipsychotic effect? An in vivo quantitative [123I] epidepride SPET study of amisulpride-treated patients. Am J Psychiatry. 160:1413-1420.

[215] Frankle WG, Gil R, Hackett E, et al. (2004) Occupancy of dopamine D2 receptors by the atypical antipsychotic drugs risperidone and olanzapine: theoretical implications. Psychopharmacol. (Berl) 175:473-480.

[216] Meltzer HY, McGurk SR (1999). The effects of clozapine, risperidone, and olanzapine on cognitive function in schizophrenia. Schizophren Bull. 25:233-255
[217] Hasan A, Falkai P, Wobrock T, Lieberman J, Glenthoj B et al (2013) World Federation of Societies of Biological Psychiatry (WFSBP) guidelines for biological treatment of schizophrenia, part 2: update 2012 on the long-term treatment of schizophrenia and management of antipsychotic-induced side effects. World J Biol Psychiatry. 149:2-44.

[218] Keefe RS, Silva SG, Perkins DO, Lieberman JA (1999). The effects of atypical antipsychotic drugs on neurocognitive impairment in schizophrenia: a review and meta-analysis. Schizophr Bull. 25:201-222.

[219] Perez SM, Lodge DJ (2014) New approaches to the management of schizophrenia: focus on aberrant hippocampal drive of dopamine pathways Drug Des. Devel. Ther. 8:887-896.

[220] Leucht S, Komossa K, Rummel-Kluge C et al., (2009) A meta-analysis of head-to-head comparisons of second-generation antipsychotics in the treatment of schizophrenia,” Am. J Psychiatry, 166:152-163.

[221] Kapur S, Zipursky R, Jones C, Shammi CS, Remington G et al (2000) A positron emission tomography study of quetiapine in schizophrenia: a preliminary finding of an antipsychotic effect with only transiently high dopamine D2 receptor occupancy, Arch Gen Psychiatry. 57: 553-559.

[222] Schotte A, Janssen PFM, Gommeren W et al (1996) Risperidone compared with new and reference antipsychotic drugs: in vitro and in vivo receptor binding. Psychopharmacol. 124:57-73.

[223] Kapur S, Seeman P (2001) Does fast dissociation from the dopamine D2 receptor explain the action of atypical antipsychotics?: a new hypothesis, Am J. Psychiatry. 158:360-369.

[224] Tandon R, Nasrallah HA, Keshavan MS (2010) Schizophrenia, "Just the Facts" 5. Treatment and prevention past, present, and future. Schizophrenia Res. 122:1-23,

[225] Divac N, Marić NP, Damjanović A, Jovanović AA, Jašović-Gašić M et al (2009) Use or underuse of therapeutic guidelines in psychiatry? Psychiatria Danubina. 21:224-229.

[226] Goff DC, Midha KK, Sarid-Segal O. (1995) A placebo-controlled trial of fluoxetine added to neuroleptic in patients with schizophrenia. Psychopharmacol. (Berl). 117:417-423.

[227] Newman-Tancredi (2010). The importance of 5-HT1A receptor agonism in antipsychotic drug action: rationale and perspectives. Curr Opin Investig Drugs. 11:802-12.

[228] Newman-Tancredi A, Kleven MS (2011) Comparative pharmacology of antipsychotics possessing combined dopamine D2 and serotonin 5-HT1A receptor properties. Psychopharmacol. (Berl). 216:451-73.

[229] Sheikhmoonesi F, Zarghami M, Bahari Saravi SF, Khalilian A, Ala S (2015) A triple-blinded, randomized, placebo-controlled trial to examine the efficacy of buspirone added to typical antipsychotic drugs in patients with chronic schizophrenia. J Res Med Sci. 20:140-5.

[230] Stone JM (2011) Glutamatergic antipsychotic drugs: a new dawn in the treatment of schizophrenia? Ther Adv 
Psychopharmacol. 1:5-18.

[231] Lorrain DS, Baccei CS, Bristow LJ, Anderson JJ, Varney MA ( 2003) Effects of ketamine and N-methyl-D-aspartate on glutamate and dopamine release in the rat prefrontal cortex: modulation by a group II selective metabotropic glutamate receptor agonist LY379268 Neurosci. 117:697-706.

[232] Tsai GE, Lin P-Y (2010) Strategies to enhance $\mathrm{N}$-methyl-D-aspartate receptor-mediated neurotransmission in schizophrenia, a critical review and meta-analysis. Curr Pharm Des. 16:522-37.

[233] Weiser M, Heresco-Levy U, Davidson M, Javitt DC, Werbeloff $\mathrm{N}$ et al (2012) A multicenter, add-on randomized controlled trial of low-dose d-serine for negative and cognitive symptoms of schizophrenia. J Clin Psychiatry. 73:e728-34.

[234] Umbricht D, Alberati D, Martin-Facklam M, Borroni E, Youssef EA et al (2014) Effect of bitopertin, a glycine reuptake inhibitor, on negative symptoms of schizophrenia: a randomized, double-blind, proof-of-concept study. JAMA Psychiatry. 71:637-46.

[235] Goff DC (2014) Bitopertin: the good news and bad news. JAMA Psychiatry. 71:621-2.

[236] Fujita Y, Ishima T, Kunitachi S, et al (2008) Phencyclidine-induced cognitive deficits in mice are improved by subsequent subchronic administration of the antibiotic drug minocycline. Prog Neuropsychopharmacol Biol Psychiatry. 32:336-9.

[237] Miyaoka T, Yasukawa R. (2008) Minocycline as Adjunctive Therapy for Schizophrenia: An open-label study. Clin. doi: 10.1097/wnf.0b013e3181593d45.

[238] Liu F, Guo X, Wu R et al (2014) Minocycline supplementation for treatment of negative symptoms in early-phase schizophrenia: a double blind, randomized, controlled trial. Schizophr Res. 153:169-76.

[239] Monte AS, de Souza GC, McIntyre RS et al (2013) Prevention and reversal of ketamine-induced schizophrenia related behavior by minocycline in mice: Possible involvement of antioxidant and nitrergic pathways. J Psychopharmacol. 27:1032-43

[240] Bobanovic M, Bird DC, Robertson HA, Dursun SM. (2000) Blockade of phencyclidine-induced effects by a nitric oxide donor. Br J Pharmacol. 1005-1012.

[241] Hallak JEC, Maia-de-Oliveira JP, Abrao J et al (2013) Rapid improvement of acute schizophrenia symptoms after intravenous sodium nitroprusside: a randomized, double-blind, placebo-controlled trial. JAMA psychiatry. 70:668-76.

[242] Manzoni O, Prezeau L, Desagher S et al (1992) Sodium nitroprusside blocks NMDA receptors via formation of ferrocyanide ions. Neuroreport. 3.

[243] Mezler M, Geneste H, Gault L, Marek GJ (2010) LY-2140023, a prodrug of the group II metabotropic glutamate receptor agonist LY-404039 for the potential treatment of schizophrenia. Curr Opin Investig Drugs. $11: 833-45$
[244] Rorick-Kehn LM, Johnson BG, Burkey JL, Wright RA, Calligaro DO et al (2007). Pharmacological and pharmacokinetic properties of a structurally novel, potent, and selective metabotropic glutamate $2 / 3$ receptor agonist: in vitro characterization of agonist

(-)-(1R,4S,5S,6S)-4-amino-2-sulfonylbicyclo[3.1.0]-hexan e-4,6-dicarboxylic acid (LY404039). J. Pharmacol Exp Ther. 321:308-17.

[245] Patil ST, Zhang L, Martenyi F, Lowe SL, Jackson KA et al (2007) Activation of mGlu2/3 receptors as a new approach to treat schizophrenia: a randomized Phase 2 clinical trial". Nature Med. 13:1102-7.

[246] Kinon BJ, Zhang L, Williams JE et al (2010) LY2140023 monohydrate: An agonist at the MLGU2/3 receptor for the treatment of schizophrenia. Schizophr Res. 117:379-379.

[247] Hosák L, Libiger J. (2002) Antiepileptic drugs in schizophrenia: a review. Eur J. Psychiatry. 17:371-378.

[248] Deakin JFW, Lees J, McKie S et al (2008) Glutamate and the neural basis of the subjective effects of ketamine: a pharmaco-magnetic resonance imaging study. Arch Gen Psychiatry. 65:154-164.

[249] Dursun S, McIntosh D, Milliken H. (1999) Clozapine plus lamotrigine in treatment-resistant schizophrenia. Arch Gen. $245: 372-3$

[250] Tiihonen J, Halonen P, Wahlbeck K et al (2005) Topiramate add-on in treatment-resistant schizophrenia: a randomized, double-blind, placebo-controlled, crossover trial. J Clin Psychiatry. 66:1012-1015.

[251] Gibbs JW, Sombati S, DeLorenzo RJ, Coulter DA (2000) Cellular actions of topiramate: blockade of kainate-evoked inward currents in cultured hippocampal neurons. Epilepsia. 4:S10-S16.

[252] Deutsch SI, Rosse RB, Billingslea EN et al (2002) Topiramate antagonizes MK-801 in an animal model of schizophrenia. Eur J Pharmacol. 449:121-125.

[253] Dursun SM, Deakin JFW. (2001) Augmenting antipsychotic treatment with lamotrigine or topiramate in patients with treatment-resistant schizophrenia: a naturalistic caseseries outcome study. J Psychopharmacol. 15:297-301.

[254] Hahn MK, Cohn T, Teo C, Remington G (2013) Topiramate in schizophrenia: a review of effects on psychopathology and metabolic parameters. Clin Schizophr Relat Psychoses. 6:186-96.

[255] Bumb JM, Enning F, Leweke FM (2013) Repurposed Drugs for the Treatment of Schizophrenia and Bipolar Disorders. Curr. Topics in Med Chem. 13:000-00011568-0266

[256] Lee HM, Kim Y (2016) Drug repurposing is a new opportunity for developing drugs against neuropsychiatric disorders. Schizophr Res Treatment. 2016:6378137.

[257] Suvisaari J, Loo BM, Saarni SE, Haukka J, Peral J et al (2011) Inflammation in psychotic disorders: a population-based study. Psychiatry Res. 189:305-11.

[258] Saetre P, Emilsson L, Axelsson E, Kreuger J, Lindholm E et al (2007) Inflammation-related genes up-regulated in schizophrenia brains. BMC Psychiatry 7:46.

[259] Kirkpatrick B, Miller BJ (2013) Inflammation and 
Schizophrenia Schizophr Bull 39:1174-1179.

[260] Laan W, Grobbee DE, Selten JP, Heijnen CJ, Kahn RS et al (2010) Adjuvant aspirin therapy reduces symptoms of schizophrenia spectrum disorders: results from a randomized, double-blind, placebo-controlled trial. J Clin Psychiatry 71:520-7.

[261] Müller N, Krause D, Dehning S, Musil R, Schennach-Wolff $R$ et al (2010) Celecoxib treatment in an early stage of schizophrenia: results of a randomized, double-blind, placebo-controlled trial of celecoxib augmentation of amisulpride treatment. Schizophr Res. 121:118-24.

[262] Aïd S, Bosetti F (2011). Targeting cyclooxygenases-1 and -2 in neuroinflammation: Therapeutic implications. Biochimie, 93:46-51

[263] Zheng W ,Cai DB, Yang XH, Ungvari GS, Ng CH, Müller et al (2017) Adjunctive celecoxib for schizophrenia: A meta-analysis of randomized, double-blind, placebo-controlled trials. J Psychiatry Res. 92:139-146.

[264] Citrome L (2009) Adjunctive lithium and anticonvulsants for the treatment of schizophrenia: what is the evidence? Expert Rev Neurother. 9:55-71.

[265] Sim K, Yong KH, Chan YH, Tor PC, Xiang YT et al (2010) Adjunctive mood stabilizer treatment for hospitalized schizophrenia patients: Asia psychotropic prescription study (2001-2008). Int J Neuropsychopharmacol. 14:1157-64.

[266] Suzuki T, Uchida H, Takeuchi H, Nakajima S, Nomura K et al (2009) Augmentation of atypical antipsychotics with valproic acid. An open-label study for most difficult patients with schizophrenia. Hum Psychopharmacol. 24:628-38.

[267] Uribe E, Sánchez-Mendoza E, Nieves N, Merchor G (2016) Neonatal Administration of Memantine Enhances Social Cognition in Adult Rats Subjected to Early Maternal Deprivation. Exp Neurobiol. 25:328-332.

[268] Kishi, T., Matsuda, Y. \& Iwata, N. (2017) Memantine add-on to antipsychotic treatment for residual negative and cognitive symptoms of schizophrenia: a meta-analysis. Psychopharmacol. 234 (14): 2113-2125.

[269] Light GA, Zhang W, Joshi YB, Bhakta S, Talledo JA et al (2017) Single-Dose memantine improves cortical oscillatory response dynamics in patients with schizophrenia. Neuropsychopharmacol. In press, doi: 10.1038/npp.2017.81.

[270] Omranifard V, Rajabi F, Mohammadian-Sichani M, Maracy MR (2017). The effect of add-on memantine on positive, negative and depressive symptoms of schizophrenia: a doubleblind, randomized, controlled trial. Actas Esp Psiquiatr. 45:108-15.

[271] Hinkelmann K, Yassouridis A, Kellner M, Jahn H, Wiedemann K, Raedler TJ. (2013) No effects of antidepressants on negative symptoms in schizophrenia. $\mathbf{J}$ Clin Psychopharmacol 33:686-690.

[272] Poyurovsky M, Pashinian A, Weizman R, Fuchs C, Weizman A (2006) Low-dose mirtazapine: a new option in the treatment of antipsychotic-induced akathisia. A randomized, double-blind, placebo- and propranolol-controlled trial. Biol Psychiatry. 59:1071-7.

[273] Vidal C, Reese C, Fischer BA, Chiapelli J, Himelhoch S (2015) Meta-Analysis of Efficacy of Mirtazapine as an
Adjunctive Treatment of Negative Symptoms in Schizophrenia. Clin Schizophr Relat Psychoses. 9:88-95.

[274] Shiloh R, Zemishlany Z, Aizenberg D, Valevski A, Bodinger L et al (2002) Mianserin or placebo as adjuncts to typical antipsychotics in resistant schizophrenia. Int Clin Psychopharmacol. 17:59-64.

[275] Shireen E, Haleem DJ (2011) Reversal of haloperidol-induced motor deficits by mianserin and mesulergine in rats. Pak. J. Pharm. Sci., 24:7-12.

[276] Rosenthal MH, Bryant SL (2004) Benefits of adjunct modafinil in an open-label, pilot study in patients with schizophrenia. Clin Neuropharmacol. 27:38-43.

[277] Scoriels L, Barnett JH, Murray GK, Cherukuru S, Fielding $M$ et al (2011) Effects of modafinil on emotional processing in first episode psychosis. Biol Psychiatry. 69:457-64.

[278] Henderson DC, Freudenreich O, Borba CP, Wang X, Copeland PM et al (2011) Effects of modafinil on weight, glucose and lipid metabolism in clozapine-treated patients with schizophrenia. Schizophr Res. 130:53-6.

[279] Kasper S, Barnas C, Heiden A, Volz HP, Laakmann G et al (1997) Pramipexole as adjunct to haloperidol in schizophrenia. Safety and efficacy. Eur Neuropsychopharmacol. 7: 65-70

[280] Mahadik SP, Gowda S (1996) Antioxidants in the treatment of schizophrenia. Drugs Today 32:1-13.

[281] Reddy R, Reddy R (2011) Antioxidant Therapeutics for Schizophrenia. Antioxidants and Redox Signaling. 15:2047-55.

[282] Mahadik SP, Scheffer RE (1996) Oxidative injury and potential use of antioxidants in schizophrenia. Prostaglandins, Leukotrienes and Essential Fatty Acids. $55: 45-54$

[283] Berk M, Copolov D, Dean O, Lu K, Jeavons S et al (2008) $\mathrm{N}$-acetyl cysteine as a glutathione precursor for schizophrenia - a double-blind, randomized, placebo-controlled trial. Biol Psychiatry. 64: 361-8.

[284] Bulut M, Savas HA, Altindag A, Virit O, Dalkilic A (2009) Beneficial effects of $\mathrm{N}$-acetylcysteine in treatment resistant schizophrenia. World J Biol Psychiatry. 10:626-8.

[285] Assisi A, Banzi R, Buonocore C, Capasso F, Di Muzio V et al (2006) Fish oil and mental health: the role of n-3 long-chain polyunsaturated fatty acids in cognitive development and neurological disorders. Int Clin Psychopharmacol. 21:319-36.

[286] Pisano S, Gritti A, Catone G, Pascotto A (2013) Antipsychotic-induced dyslipidemia treated with omega 3 fatty acid supplement in an 11-year-old psychotic child: a 1-year follow-up. J Child Adolesc Psychopharmacol. 23:139-41

[287] Pawełczyk T, Grancow M, Kotlicka-Antczak M, Trafalska E, Gębski P et al (2015) Omega-3 fatty acids in first-episode schizophrenia - a randomized controlled study of efficacy and relapse prevention (OFFER): rationale, design, and methods. BMC Psychiatry. 15:97.

[288] Emsley R, Myburgh C, Oosthuizen P, van Rensburg SJ (2002) Randomized, placebo-controlled study of 
ethyl-eicosapentaenoic acid as supplemental treatment in schizophrenia. Am J Psychiatry. 159:1596-8

[289] Berger GE, Proffitt TM, McConchie M, Yuen H, Wood SJ et al (2007) Ethyl-eicosapentaenoic acid in first-episode psychosis: a randomized, placebo-controlled trial. J Clin Psychiatry. 68:1867-75.

[290] Häfner H (2003) Gender differences in schizophrenia Psychoneuroendocrinol. 2:17-54.

[291] Seeman MV (1996) The role of estrogen in schizophrenia, J. Psychiatr Neurosci. 21:123-127.

[292] Gogos A, Kwek P, van den Buuse M (2012) The role of estrogen and testosterone in female rats in behavioral models of relevance to schizophrenia," Psychopharmacol. 219:213-224.

[293] Kulkarni J, Gavrilidis E, Worsley R, Van Rheenen T, Hayes E (2013) The role of estrogen in the treatment of men with schizophrenia. Int J Endocrinol Metab. 11:129-36.

[294] Bergemann N, Parzer P, Runnebaum B, Resch F, Mundt C (2007) Estrogen, menstrual cycle phases, and psychopathology in women suffering from schizophrenia. Psychol Med. 37:1427-36.

[295] Ghafari E, Fararouie M, Shirazi HG, Farhangfar A, Ghaderi F et al (2013) Combination of estrogen and antipsychotics in the treatment of women with chronic schizophrenia. Clin Schizophr Relat Psychoses. 6:172-6.

[296] Kulkarni J, Gurvich C, Lee S.J, Gilbert H, Gavrilidis E et al (2010) Piloting the effective therapeutic dose of adjunctive selective estrogen receptor modulator treatment in postmenopausal women with schizophrenia. Psychoneuroendocrinol. 35:1142-7.

[297] Weickert TW, Weinberg D, Lenroot R, Catts SV, Wells R et al (2015) Adjunctive raloxifene treatment improves attention and memory in men and women with schizophrenia. Mol Psychiatry. 20:685-94.

[298] Park HJ, Park JK, Kim SK, Cho AR, Kim JW et al (2011) Association of polymorphism in the promoter of the melatonin receptor $1 \mathrm{~A}$ gene with schizophrenia and with insomnia symptoms in schizophrenia patients. J Mol Neurosci. 45:304-08

[299] Romo-Nava F, Alvarez-Icaza GD, Fresán-Orellana A, Saracco Alvarez R et al (2014) Melatonin attenuates antipsychotic metabolic effects: an eight-week randomized, double-blind, parallel-group, placebo-controlled clinical trial. Bipolar Disord. 16:410-21.

[300] Anderson G, Maes M (2012) Melatonin: an overlooked factor in schizophrenia and in the inhibition of anti-psychotic side effects. Metab Brain Dis. 27:113-9.

[301] Averbeck BB, Bobin T, Evans S, Shergill SS (2011) Emotion recognition and oxytocin in patients with schizophrenia. Psychol Med. 1-8.

[302] Feifel D, Macdonald K, Cobb P, Minassian A (2012) Adjunctive intranasal oxytocin improves verbal memory in people with schizophrenia. Schizophr. Res. 139:207-10.

[303] Modabbernia A, Rezaei F, Salehi B, Jafarinia M, Ashrafi $M$ et al (2013) Intranasal oxytocin as an adjunct to risperidone in patients with schizophrenia: an 8-week, randomized, double-blind, placebo-controlled study. CNS Drugs. 27:57-65.

[304] Ehrenreich H, Hinze-Selch D, Stawicki S, Aust C, Knolle-Veentjer $S$ et al (2007) Improvement of cognitive functions in chronic schizophrenic patients by recombinant human erythropoietin. Mol Psychiatry. 12:206-20.

[305] Wustenberg T, Begemann, Bartels C, Gefeller O, Stawicki $S$ et al (2011) Recombinant human erythropoietin delays loss of gray matter in chronic schizophrenia. Mol Psychiatry 16:26-36, 1.

[306] Ritsner MS (2011) The clinical and therapeutic potentials of dehydroepiandrosterone and pregnenolone in schizophrenia. Neurosci. 191:91-100.

[307] Strous RD. Stryjer R, Maayan R, Gal G, Viglin D et al (2007) Analysis of clinical symptomatology, extrapyramidal symptoms and neurocognitive dysfunction following dehydroepiandrosterone (DHEA) administration in olanzapine treated schizophrenia patients: a randomized, double blind placebo controlled trial. Psychoneuroendocrinol. 32:96-105.

[308] Shohag H, Ullah A, Qusar S, Rahman M, Hasnat A (2012) Alterations of serum zinc, copper, manganese, iron, calcium, and magnesium concentrations and the complexity of interelement relations in patients with obsessive-compulsive disorder. Biol Trace Elem Res. 148:275-80.

[309] Rahman A, Azad MA, Hossain I, Qusar MM, Bari W et al (2009) Zinc, manganese, calcium, copper, and cadmium level in scalp hair samples of schizophrenic patients. Biol Trace Elem Res. 127:102-8.

[310] Mortazavi M, Farzin D, Zarhghami M, Hosseini SH, Mansoori P, Nateghi G(2015) Efficacy of zinc sulfate as an add-on therapy to risperidone versus risperidone alone in patients with schizophrenia: A double-blind randomized placebo-controlled trial. Iran J Psychiatry Behav. Sci. 9:e853. 